\title{
Mechanosensitive TRPC1 Channels Promote Calpain Proteolysis of Talin to Regulate Spinal Axon Outgrowth
}

\author{
Patrick C. Kerstein, ${ }^{1}$ Bridget T. Jacques-Fricke, ${ }^{2}$ Juliana Rengifo, ${ }^{3}$ Brian J. Mogen, ${ }^{4}$ Justin C. Williams, ${ }^{4}$ \\ Philip A. Gottlieb, ${ }^{5}$ Fredrick Sachs, ${ }^{5}$ and Timothy M. Gomez ${ }^{1}$ \\ ${ }^{1}$ Department of Neuroscience and Neuroscience Training Program, University of Wisconsin, Madison, Wisconsin 53706, ${ }^{2}$ Department of Genetics, Cell \\ Biology, and Development, University of Minnesota, Minneapolis, Minnesota 55455, ${ }^{3}$ Department of Biology, Universidad ICESI, 122-135 Pance, Cali, \\ Colombia, ${ }^{4}$ Department of Biomedical Engineering, University of Wisconsin, Madison, Wisconsin 53706, and ${ }^{5}$ Department of Physiology and Biophysics, \\ State University of New York at Buffalo, Buffalo, New York 14214
}

Intracellular $\mathrm{Ca}^{2+}$ signals control the development and regeneration of spinal axons downstream of chemical guidance cues, but little is known about the roles of mechanical cues in axon guidance. Here we show that transient receptor potential canonical 1 (TRPC1) subunits assemble mechanosensitive (MS) channels on Xenopus neuronal growth cones that regulate the extension and direction of axon outgrowth on rigid, but not compliant, substrata. Reducing expression of TRPC1 by antisense morpholinos inhibits the effects of MS channel blockers on axon outgrowth and local $\mathrm{Ca}^{2+}$ transients. $\mathrm{Ca}^{2+}$ influx through MS TRPC1 activates the protease calpain, which cleaves the integrin adaptor protein talin to reduce Src-dependent axon outgrowth, likely through altered adhesion turnover. We found that talin accumulates at the tips of dynamic filopodia, which is lost upon cleavage of talin by active calpain. This pathway may also be important in axon guidance decisions since asymmetric inhibition of MS TRPC1 is sufficient to induce growth cone turning. Together our results suggest that $\mathrm{Ca}^{2+}$ influx through MS TRPC1 on filopodia activates calpain to control growth cone turning during development.

\section{Introduction}

Guidance of axons to their proper synaptic targets requires spatially and temporally precise modulation of biochemical signals within growth cones. Ionic calcium $\left(\mathrm{Ca}^{2+}\right)$ is one important intracellular signal that has complex and varied effects on the guidance of axons (Henley and Poo, 2004; Gomez and Zheng, 2006). A number of studies suggests that different $\mathrm{Ca}^{2+}$ channels on growth cones positively or negatively regulate neurite extension downstream of axon guidance cues (Hong et al., 2000; Henley and Poo, 2004). Transient receptor potential (TRP) channels are homo- and heterotetrameric cationic channels activated by diverse stimuli such as, soluble ligands, mechanical forces, temperature, and several intracellular signaling cascades (Wu et al., 2010). Interestingly, TRP channels are involved in attractive turning toward netrin and brain-derived neurotrophic factor, suggesting that $\mathrm{Ca}^{2+}$ influx through these channels may be a positive signal for neurite outgrowth ( $\mathrm{Li}$ et al., 2005; Wang and Poo, 2005). Paradoxically, myelin-associated glycoprotein and

Received May 3, 2012; revised 0ct. 18, 2012; accepted 0ct. 29, 2012.

Author contributions: P.C.K., B.T.J.-F., and T.M.G. designed research;P.C.K., B.T.J.-F., J.R., and T.M.G. performed research; B.J.M., J.C.W., P.A.G., and F.S. contributed unpublished reagents/analytic tools; P.C.K., B.T.J.-F., J.R., and T.M.G. analyzed data; P.C.K. and T.M.G. wrote the paper.

This work was supported by National Institutes of Health (NIH) NS41564 and a Dana Foundation grant to T.M.G., NIH F31NS053076 to B.T.J.-F., and NIH T32GM007507 to the Neuroscience Training Program. We thank Dr. Ching Kung (Department of Genetics, University of Wisconsin-Madison) and the members of the Gomez lab for comments on this manuscript.

The authors declare no competing financial interests.

Correspondence should be addressed to Timothy M. Gomez, University of Wisconsin School of Medicine and Public Health, 257 Bardeen Labs, 1300 University Avenue, Madison, WI 53706. E-mail: tmgomez@wisc.edu.

DOI:10.1523/JNEUROSCI.2142-12.2013

Copyright $\odot 2013$ the authors $\quad 0270-6474 / 13 / 330273-13 \$ 15.00 / 0$ bone morphogenetic protein (BMP7), which repel growing axons, also require $\mathrm{Ca}^{2+}$ influx through TRP channels (Shim et al., 2005; Wen et al., 2007). While each of these studies implicated TRPC1-subunit containing channels, the precise TRP channel involved has not been determined.

The physical properties of the cellular environment can also influence the migration of axons (Rajnicek and McCaig, 1997; Nguyen et al., 2002; Willits and Skornia, 2004), as well as nonneuronal cells (Pelham and Wang, 1997; Lo et al., 2000; Frey et al., 2006). A number of studies have suggested that substratum rigidity regulates the rate and direction of cell migration, including extending neuronal processes (Lo et al., 2000; Kostic et al., 2007). Precisely how mechanical forces influence cell motility is unclear, but a role for mechanosensitive (MS) $\mathrm{Ca}^{2+}$ channels is supported by several reports. For example, regulation of cell motility correlates with the frequency of $\mathrm{Ca}^{2+}$ transients evoked in cells, which is directly proportional to traction forces generated by cell movements (Lee et al., 1999; Doyle et al., 2004). Similarly, the frequency of $\mathrm{Ca}^{2+}$ transients at the tips of growth cone filopodia correlates with substratum adhesivity (Gomez et al., 2001). Finally, local mechanically induced $\mathrm{Ca}^{2+}$ transients have recently been shown to steer migrating cells (Wei et al., 2009), although the specific MS channels responsible for $\mathrm{Ca}^{2+}$ signals and the downstream $\mathrm{Ca}^{2+}$ effectors that regulate motility remain elusive.

Here we identify TRPC1 subunit-containing channels as MS channels on spinal neuron growth cones. We find that increasing or decreasing MS channel activity alters the rate of axon outgrowth by influencing the frequency of filopodial $\mathrm{Ca}^{2+}$ transients on rigid, but not soft, substrata. Furthermore, we find that the protease calpain is activated by $\mathrm{Ca}^{2+}$ influx through MS channels and 
reduces axon outgrowth through proteolytic cleavage of the integrin-binding protein talin. Finally, we show that asymmetric MS channel activity induces growth cone turning, suggesting that the elastic properties of the environment may influence axon outgrowth and guidance during development and regeneration in vivo.

\section{Materials and Methods}

Xenopus spinal cord culture and substrata preparation/characterization. Spinal cords were dissected from male and female stage 22-24 embryos as described previously (Gómez et al., 2003). Cultures on rigid fibronectin (FN) were plated on acid-washed glass coverslips coated directly with 10 $\mu \mathrm{g} / \mathrm{ml} \mathrm{FN}$ (Sigma). Cultures on flexible FN were plated onto acid-washed glass coverslips pretreated with polydimethylsiloxane (PDMS). PDMS was mixed 10:1 base to cross-linker, spun to a $40 \mu \mathrm{m}$ sheet, cured, and then adhered to the coverslips using an oxygen-plasma treatment. The elastic modulus of thick PDMS was determined to be $950 \mathrm{kPa}$ following the ASTM Standard D638-10 using a 5548 Instron MicroTester (Instron) with an environmental chamber. Fluorescent beads were incorporated into gels that were preconditioned in PBS for 10 min before testing. Stress data were collected directly from the Instron, while strain data were collected by time-lapse imaging of the beads suspended within the samples. Note that this PDMS is significantly softer than FN coated onto untreated glass ( $\sim 60 \mathrm{GPa}$; Shackelford and Alexander, 2001). Also, PDMS stiffness $<200 \mu \mathrm{m}$ depends on thickness, which we corrected for by measuring the thickness of our samples with a ZYGO interferometer (Zygo) and recalculating the Young's modulus as previously described (Liu et al., 2009). Further, thin layers of PDMS ( $8 \mu \mathrm{m})$ were spun to generate stiffer PDMS substrata $(1.8 \mathrm{MPa})$. All data processing was done in MATLAB (MathWorks). Explant cultures were imaged after 16-24 h in culture. Perfusion chambers to allow rapid exchange of solutions were made as previously described (Gómez et al., 2003).

Blastomere injections. A TRPV4 translation-blocking morpholino was designed by Gene Tools with the following sequence: $5^{\prime}$ ATCTGCCATATTTTACACCTGGTAC-3' from the 5' UTR of TRPV4 that we determined by rapid amplification of $5^{\prime}$ cDNA ends (5' RACE, Ambion). The ability of this morpholino to reduce TRPV4 expression was verified by Western blot (see Fig. $5 a$ ). The TRPC1 morpholino sequence used was 5' -CTCTGATAAAGAGCAGCCATGATGA-3', as described previously (Shim et al., 2005; Wang and Poo, 2005; Wen et al., 2007). A standard control morpholino was used with the following sequence: 5'-CCTCTTACCTCAGTTACAATTTATA-3'. Fertilized embryos were injected at the four-cell or eight-cell stage with mixtures of morpholinos (17 ng/blastomere) and a fluorescent lineage tracer (20 $\mathrm{ng} /$ blastomere [tetramethylrhodamine isothiocyanate (TRITC) dextran] or mRNA (1 ng) encoding green fluorescent protein (GFP) or mCherry. Two different concentrations of the TRPC1 morpholino have been used previously (Shim et al., 2005; Wang and Poo, 2005). The concentration we use here is comparable to the concentrations used to knock down TRPC1 expression by $\sim 50 \%$ (Shim et al., 2005). KD-Src mRNA was injected at $70 \mathrm{pg} /$ blastomere with the fluorescent lineage tracer, TRITC dextran. EGFP-Talin and eGFP-Talin L432G (from Dr. Anna Huttenlocher, University of Wisconsin-Madison) were both injected as DNA at $70 \mathrm{pg} /$ blastomere. Embryos that appeared grossly normal $24 \mathrm{~h}$ postfertilization were used to make spinal cord explant cultures.

Neurite outgrowth imaging and analysis. To determine rates of neurite outgrowth, images were captured every minute using a Nikon Eclipse microscope with an X-Cite 120 Series fluorescence illumination system (Lumen Dynamics). GsMTx4 was chemically synthesized and folded from a linear peptide by SynPep. KN62, PP2, and calpastatin peptide (CPI) were from Calbiochem, Cyclosporin A (CsA) was from Biomol, and ALLM was from Sigma-Aldrich. The growth rates of neurites were measured $30 \mathrm{~min}$ before and after addition or removal of a pharmacological blocker. For experiments using multiple inhibitors, time-lapse images were collected over 15 min periods before treatment, after the addition of the first inhibitor, and after addition of the second inhibitor. Analysis was performed with MetaMorph (Universal Imaging) and ImageJ (W. Rasband, NIH, Bethesda, MD) software.
Turning assays. Growth cone turning experiments involving local application of GsMTx4 were performed with a $40 \times$ air objective (NA 1.4) on a Zeiss Axiovert microscope equipped with a Cool-snap HQ CCD camera (Roper Scientific). Micropipettes with a tip diameter of $1 \mu \mathrm{m}$ were filled with either $1 \times$ modified Ringer's culture medium or medium containing $1 \mathrm{~mm}$ GsMTx4. Micropipettes were positioned at a distance of $100 \mu \mathrm{m}$ from the growth cone leading edge at $45^{\circ}$ with respect to the neurite axis, or $90^{\circ}$ for experiments including Fluo- $4 \mathrm{Ca}^{2+}$ imaging using total internal reflection fluorescence (TIRF) microscopy. An electronically gated pressure application system (World Precision Instruments) controlled by a programmable pulse generator (Master 8; A.M.P.I,) was used to generate $50 \mathrm{~ms}$ pulses with a positive pressure of $6 \mathrm{psi}$ at a frequency of $2 \mathrm{~Hz}$. Using a pulsatile ejection of an FITC-dextran solution we estimated that the concentration gradient across a $10 \mu \mathrm{m}$ growth cone positioned $50 \mu \mathrm{m}$ from the micropipette tip to be $\sim 25-30 \%$. Images were captured and analyzed as previously described (Robles et al., 2005).

High-speed $\mathrm{Ca}^{2+}$ imaging and analysis. TIRF $\mathrm{Ca}^{2+}$ imaging was used to examine $\mathrm{Ca}^{2+}$ dynamics within filopodia of growth cones. An inverted Nikon Eclipse TE2000-E microscope was equipped with a $100 \times$ NA 1.5 TIRF objective, an Argon laser (CVI; Melles Griot), multidimensional stage (Prior Scientific), and an Evolve EMCCD camera (Photometrics). Cultured neurons were loaded with a fluorogenic $\mathrm{Ca}^{2+}$ indicator, Fluo-4 AM ( $4 \mu \mathrm{M}$; Invitrogen). Fluo-4 fluorescence intensity was captured every $100 \mathrm{~ms}$ for $1 \mathrm{~min}$ pretreatment and post-treatment using the stream acquisition function in the MetaMorph software (Molecular Devices). Off-line analysis of filopodial $\mathrm{Ca}^{2+}$ transients was done using the ImageJ software. Only $\mathrm{Ca}^{2+}$ transients that originated within filopodia and had a fluorescent intensity that was threefold larger than the baseline noise were scored as filopodial $\mathrm{Ca}^{2+}$ transients.

Ratiometric $\mathrm{Ca}^{2+}$ imaging and analysis. To examine intracellular $\mathrm{Ca}^{2+}$ concentration during removal of aminoglycoside antibiotics or osmotic changes, neurons were loaded with cell-permeant fura-2 AM ( $5 \mu \mathrm{M}$; Invitrogen) for $30 \mathrm{~min}$. Isotonic (219.7 $\pm 0.6 \mathrm{mOsm} / \mathrm{kg}$ average $)$ and hypotonic solutions ( $119.0 \pm 0 \mathrm{mOsm} / \mathrm{kg}$ average, $46 \%$ hypotonic) were created as described previously (Jacques-Fricke et al., 2006). Images were captured every $5 \mathrm{~s}$ on a Zeiss Axiovert microscope with a $40 \times$ Fluorite objective (NA 1.4). For each ratio image used for measurements, background subtraction was performed with MetaMorph using a selected cell-free region. Intracellular calcium concentrations were calculated as previously described (Grynkiewicz et al., 1985). MetaMorph and ImageJ software were used for acquisition and analysis respectively.

$t$-BOC proteolysis assay. Xenopus neurons were incubated with 10 $\mu \mathrm{M}$ 7-amino-4-chloro-methylcoumarin, t-BOC-L-leucyl-L-methionine amide (t-BOC; Invitrogen) in $0.01 \%$ pluronic acid $/ 0.1 \%$ dimethylsulfoxide in modified Ringer's solution. Uncleaved t-Boc is nonfluorescent until it becomes internalized and is cleaved by intracellular proteases, including active calpain (Alderton and Steinhardt, 2000), unquenching the fluorescence of the coumarin fluorophore. Coumarin fluorescence was monitored using a $40 \times$ oil-immersion objective on an inverted Nikon Eclipse TE2000-E microscope equipped with a Prior Lumen 200PRO halide lamp filtered through $350 \pm 25 \mathrm{~nm}$ excitation and $460 \pm$ $25 \mathrm{~nm}$ emission filters (Chroma Technology). Coumarin fluorescence intensity within growth cones was captured every minute for $30 \mathrm{~min}$ for all experimental conditions beginning at the time of $\mathrm{t}-\mathrm{BOC}$ addition.

Acquisition and analysis of Talin dynamics. Neurons expressing eGFPTalin and eGFP-Talin L432G were imaged by TIRF. In some cases TRITC dextran was imaged as a volume control. Time-lapse images of expressing growth cones were acquired every $5 \mathrm{~s}$ for $10 \mathrm{~min}$ before and after the removal of aminoglycoside antibiotics (AGAs). All analyses were conducted off-line using ImageJ software (W. Rasband, NIH, Bethesda, MD). Talin assembly at the tips of filopodia was quantified by first setting the intensity threshold to twice that of the average filopodial shaft intensity. Talin assembly at filopodial tips was measured when fluorescence intensity at tips exceeded the threshold. The duration of each Talin assembly event was calculated as the time tip fluorescence exceeded the set threshold. The region of interest of the filopodial tip was set using the DIC or TRITC channel for each respective time point.

Immunocytochemistry. For immunocytochemistry (ICC), spinal neuron cultures were fixed in $4 \%$ paraformaldehyde in Krebs sucrose fixative 

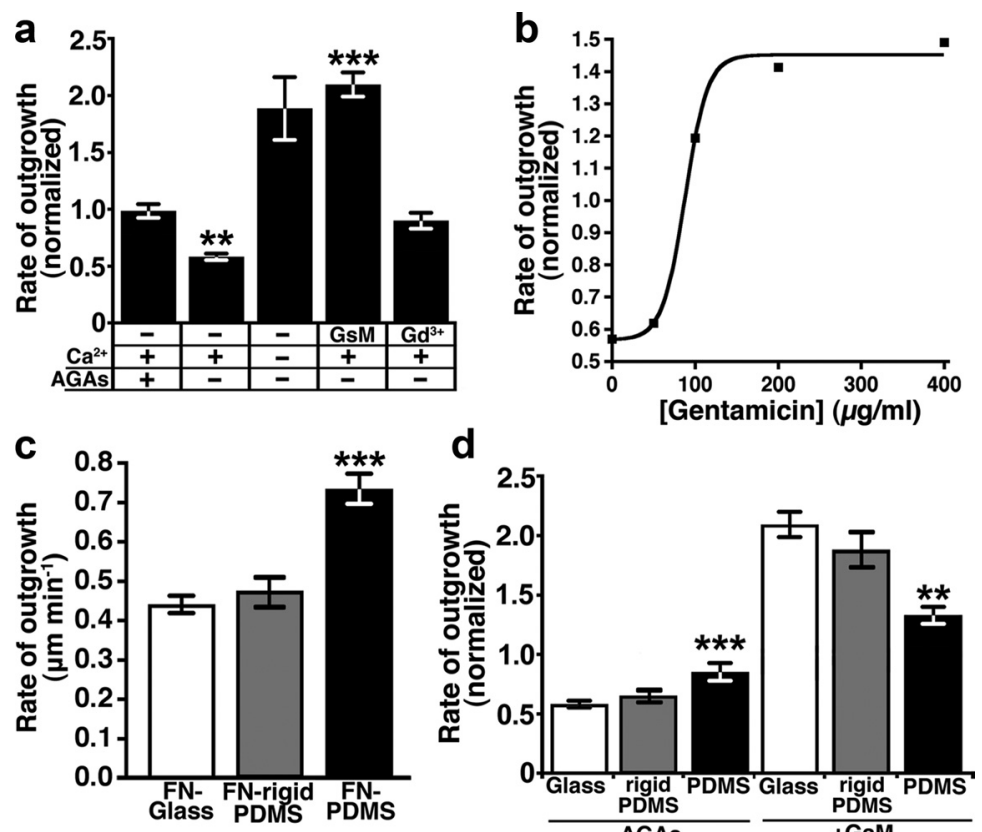

d

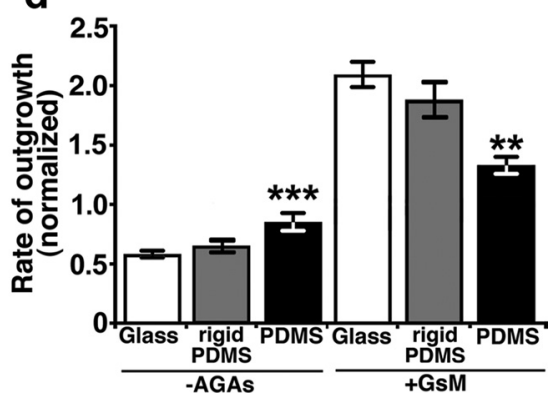

Figure 1. The rate of neurite outgrowth depends on MS channel activity and substratum elasticity. $\boldsymbol{a}$, The rate of outgrowth of Xenopus spinal axons on FN-coated glass during a control media wash (with AGAs, $n=61$ ) and during the removal of AGAs in the presence of $2 \mathrm{mM} \mathrm{Ca}^{2+}(n=34), 0 \mathrm{Ca}^{2+}(n=16), 10 \mu \mathrm{MGMTx} 4(\mathrm{GSM}, n=82)$, or $100 \mu \mathrm{M} \mathrm{Gd}{ }^{3+}(n=44)$ normalized to the precondition rate of outgrowth. Note a significant decrease in the rate of neurite outgrowth when AGAs are removed in $2 \mathrm{~mm} \mathrm{Ca}{ }^{2+}$ $\left({ }^{* *} p<0.01\right)$, but a significant increase in the rate of neurite outgrowth with addition of the MS channel blocker, GSMTx4 ${ }^{* * *} p<$ $0.001)$. $\boldsymbol{b}$, Dose-dependent effects of gentamicin on the rate of neurite outgrowth ( $n \geq 16$ for each concentration). $\boldsymbol{c}$, The basal rate of neurite outgrowth of neurons cultured on FN coated onto rigid substrata is significantly slower compared with flexible FN (see Materials and Methods; ${ }^{* * *} p<0.001, n \geq 34$ ). $\boldsymbol{d}$, The effects of pharmacologically altering MS channel activity depends on the elasticity of the substratum. The rate of axon extension is reduced by activating MS channels ( - AGAs) on rigid PDMS-FN $(n=40)$ and FN glass ( $n=35)$, but not on flexible FN $(n=45)$. Acceleration of neurite outgrowth with the addition of GsMTx4 is most pronounced on FN glass $(n=82)$ and FN-rigid PDMS $(n=56)$, but to a lesser degree on FN-flexible PDMS $(n=45) .{ }^{* *} p<0.01$ and $^{* * *} p<0.001$ compared with neurons on glass. All statistical analysis was completed with a Kruskal-Wallis test with a Dunn's multiple-comparison test.

(Dent and Meiri, 1992), permeabilized with $0.1 \%$ Triton X-100, and blocked in $1.0 \%$ fish gelatin in CMF-PBS for $1 \mathrm{~h}$ at room temperature. Primary antibodies were used at the following dilutions in blocking solution: 1:500 phospho-Y118 Paxillin (BioSource), 1:500 Talin (BioSource), and 1:500 TRPC1 (0.98 mg/ml stock; Covance) antibodies. The TRPC1 antibody was prepared by Covance from peptide with a Xenopus-specific sequence of CVGIFCEQQSNNTFHSFTGT. The sequence was selected using previous sequences that were successful in mammalian tissues (Xu et al., 2005). Alexa Fluor-conjugated secondary antibodies were purchased from Invitrogen and used at 1:250 in blocking solution. Included with secondary antibodies was Alexa-647 phalloidin (1: 100; Invitrogen) to label filamentous actin (F-actin). High-magnification images of fixed samples were acquired using a $60 \times / 1.45 \mathrm{NA}$ objective lens on an Olympus Fluoview 500 laser-scanning confocal system mounted on an AX-70 upright microscope. Samples were imaged at $2-2.5 \times$ zoom (pixel size $=165-200 \mathrm{~nm}$ ). Image processing was complete off-line using ImageJ.

Western blot. The TRPV4 polyclonal antibody was raised by Harlan Bioproducts for Science using a peptide (QRQENAQNWKKD) created by the University of Wisconsin Biotechnology Center (Madison, WI). Two cells of four-cell blastomeres were injected with the TRPV4 morpholino, ranging from 1-4 $\mathrm{nl}$ of $1 \mathrm{~mm}$ stock solution ( $17 \mathrm{ng} / \mathrm{blastomere}$ ). Membrane fractions were prepared from the dorsal sections of an average of 15 embryos for each condition according to the following protocol: homogenize embryos in buffer A (50 mM Tris/ $\mathrm{HCl}, \mathrm{pH}$ 7.25/250 mM sucrose/1 mm EGTA/1 mm dithiothreitol (DTT)/0.1 mm PMSF/ protease inhibitor mixture; Roche), centrifuge at $4500 \times g$ for $15 \mathrm{~min}$, then centrifuge the resulting supernatant at $160,000 \times g$ for $1 \mathrm{~h}$ to pellet. All centrifugation procedures were performed at $4^{\circ} \mathrm{C}$. Resuspend pellet in buffer B (20 mM Tris/HCl, pH 7.25/300 mm sucrose/1 mm EGTA/1 mm
DTT/0.1 mм PMSF/protease inhibitor mixture). The TRPV4 primary antibody was used at 1:500, secondary horseradish peroxidase antibody (Santa Cruz Biotechnology) was used at 1:5000. Membrane was stripped with Re-blot (Millipore Bioscience Research Reagents) and probed with 8C8 antibody for $\beta 1$ integrin (1:100; Developmental Studies Hybridoma Bank).

Statistical analysis. For all datasets the variance was reported as \pm SEM. Each dataset was first test for normality using a D'Agostino and Pearson omnibus normality test. Analysis between two groups was completed by using a unpaired Student's $t$ test (parametric) or Mann-Whitney $U$ test (nonparametric) depending on the results from the normality test. For analysis between more than two groups, we used either a one-way ANOVA with Tukey's multiple-comparison test (parametric) or Kruskal-Wallis with Dunn's multiplecomparison test (nonparametric) depending on the result from the normality test. Statistical significance for fura- $2 \mathrm{Ca}^{2+}$ imaging datasets was determined by a two-way ANOVA. All statistical significance tests were completed using Prism Software (Graphpad Software).

\section{Results}

MS ion channel activity slows axon extension on rigid substrata

Previously we showed that under our standard culture conditions, $\mathrm{Ca}^{2+}$ influx through MS ion channels, is partially suppressed by AGAs (Jacques-Fricke et al., 2006). AGAs such as gentamicin and streptomycin are commonly used antibiotics, but are also known to be potent blockers of MS ion channels (Kroese et al., 1989). Therefore, we exploited these conditions to examine the effects on axon outgrowth of acute disinhibition of MS channels by rapid removal of AGAs. We find that reducing or removing AGAs results in a rapid and dose-dependent slowing in the rate of axon outgrowth by spinal neurons growing on FN-coated glass coverslips. (Fig. 1a,b). The inhibitory effects of MS channel activity are even greater on laminin (LN), where the baseline rate of neurite outgrowth is higher and neurons often retract in response to removing AGAs (25\% retract on LN, $n=60$, data not shown). Reduced outgrowth upon relieved inhibition of MS channels is $\mathrm{Ca}^{2+}$ dependent, as growth is accelerated in $\mathrm{Ca}^{2+}$-free solutions (Fig. 1a). Specific blockers of MS channels, GsMTx4 and gadolinium $\left(\mathrm{Gd}^{3+}\right)$ (Yang and Sachs, 1989; Ostrow et al., 2003), support growth by blocking the inhibitory effects of MS channel activity on outgrowth (Fig. 1a). In fact, neurite outgrowth is stimulated by GsMTx4 even without AGAs, suggesting that $\mathrm{Ca}^{2+}$ influx through MS channels is more effectively or specifically blocked by this treatment. These results show that rapid removal of AGAs provides a method to acutely increase the natural activity of MS ion channels in growth cones.

The elastic properties of the cellular microenvironment can influence cell motility and axon outgrowth (Lo et al., 2000; Kostic et al., 2007), possibly through activation of MS channels (Doyle et al., 2004; Wei et al., 2009). To test how neurons respond to rapid changes in MS channel activity on flexible substrata, we cultured neurons on FN-coated PDMS (see Materials and Methods). Con- 


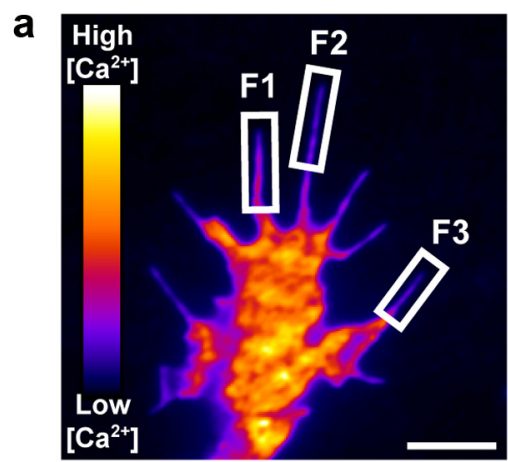

C

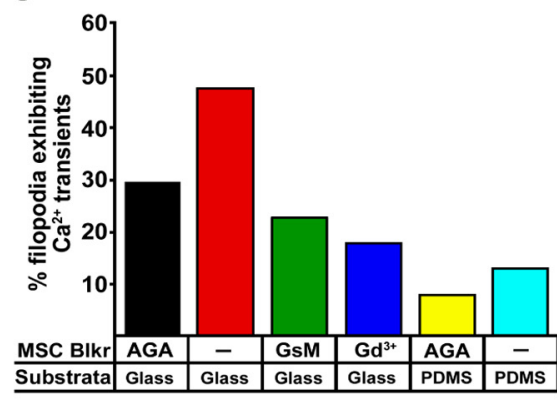

b
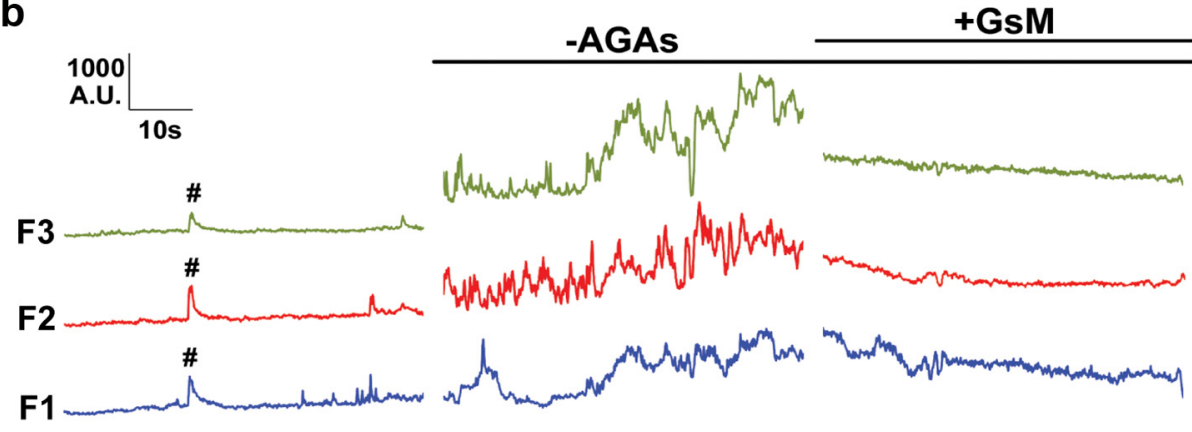

d

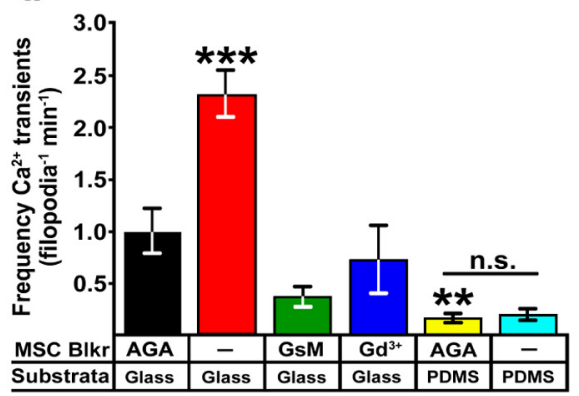

e

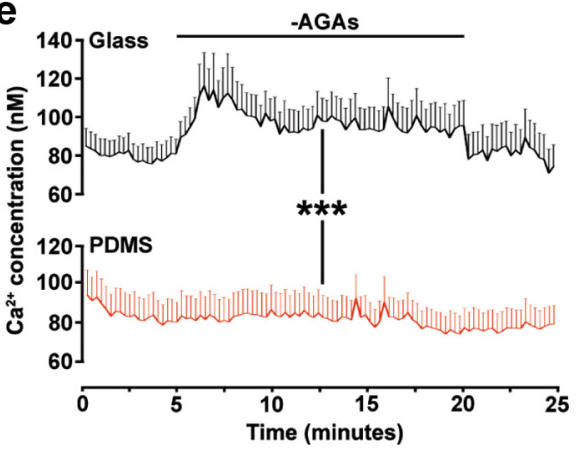

Figure 2. MS channel activity increases the incidence and frequency of filopodial $\mathrm{Ca}^{2+}$ transients and baseline $\left[\mathrm{Ca}^{2+}\right]_{\mathrm{i}} \cdot \boldsymbol{a}, \mathrm{A}$ pseudocolored Fluo-4-loaded growth cone showing regions used to measure fluorescent intensities over time. Images were captured at $10 \mathrm{~Hz}$ for 3 min during solution changes. Scale bar, $3 \mu \mathrm{m}$. $\boldsymbol{b}$, Traces of Fluo-4 fluorescent signals measured in three filopodia over 1 min periods before and after the removal of AGAs and $1 \mathrm{~min}$ after the addition of GSMTX4. \#, denotes a single global $\mathrm{Ca}^{2+}$ transient. $\boldsymbol{c}, \boldsymbol{d}$, The incidence (c) and frequency (d) of filopodial $\mathrm{Ca}{ }^{2+}$ transients were determined (see Materials and Methods) in control media $(n=290)$, in the absence of AGAs $(n=237)$, and after the addition of GsMTx4 $(n=174)$ or Gd ${ }^{3+}(n=159)$ on FN-glass substrata. Filopodial $\mathrm{Ca}^{2+}$ transients were also measured on flexible FN-PDMS with and without AGAs ( $n=103$ and 52 , respectively). ${ }^{* *} p<0.01$ and ${ }^{* * *} p<0.001$ compared with control condition (+ AGA on glass) using a Kruskal-Wallis test with a Dunn's post test. $\boldsymbol{e}$, Fura-2, a ratiometric $\mathrm{Ca}^{2+}$ indicator, was used to determine the $\left[\mathrm{Ca}^{2+}\right]_{\mathrm{i}}$ within growth cones during AGA subtraction. There was a significant increase in the baseline $\left[\mathrm{Ca}^{2+}\right]_{\mathrm{i}}$ of growth cones on $\mathrm{FN}$ glass after the removal of AGAs, but not by growth cones on FN-PDMS $\left({ }^{* * *} p<0.001\right.$, two-way ANOVA).

sistent with previous reports, we find that the basal rate of axon outgrowth is nearly twofold greater for neurons growing on flexible FN (Fig. 1c), possibly due to reduced MS channel activity on compliant substrata (Kostic et al., 2007). Consistent with reduced mechanical signaling on flexible substrata, rapid removal of AGAs does not significantly inhibit axon outgrowth (Fig. 1d). This result suggests that MS channels either cannot be further activated on flexible substrata or that their activity does not inhibit outgrowth. However, addition of GsMTx4 to neurons on flexible FN does stimulate axon outgrowth, albeit to a lesser degree compared with rigid FN (Fig. 1d). To determine whether the axon outgrowth was due to the elastic properties and not the surface quality of the FN-PDMS, we measured the outgrowth of axons grown on a thin layer of PDMS, which matches the surface quality, but not the compliance of flexible PDMS (see Materials and Methods). As expected, the basal rate of outgrowth on rigid FN-PDMS is similar to FN glass (Fig. 1c). Furthermore, the rate of neurite outgrowth was more sensitive to pharmacological activation or inhibition of MS channels compared with flexible FN-PDMS (Fig. 1d). These results suggest that substratum compliance modulates axon outgrowth, possibly by regulating MS channel activity.

\section{MS ion channel activity increases spontaneous filopodial} $\mathrm{Ca}^{2+}$ transients and baseline growth cone $\left[\mathrm{Ca}^{2+}\right]_{\mathrm{i}}$

As many MS ion channels are permeable to $\mathrm{Ca}^{2+}$ ions and $\mathrm{Ca}^{2+}$ signaling is critical for axon guidance (Gomez and Zheng, 2006), we tested whether removing AGAs alters $\mathrm{Ca}^{2+}$ signaling in growth cones. For this we measured both the frequency of fast $\mathrm{Ca}^{2+}$ transients in growth cones by fluorescence imaging of Fluo4-loaded neurons by high-speed TIRF microscopy and baseline
$\left[\mathrm{Ca}^{2+}\right]_{\mathrm{i}}$ with fura-2 by time-lapse wide-field fluorescence microscopy. Consistent with the accelerating effects of AGAs on neurite outgrowth, we find that rapid removal of AGAs leads to an immediate increase in the frequency of spontaneous filopodial $\mathrm{Ca}^{2+}$ transients (Fig. 2a,b) and baseline $\left[\mathrm{Ca}^{2+}\right]_{\mathrm{i}}($ Fig. $2 e$ ) within growth cones. $\mathrm{Ca}^{2+}$ transients occur both locally and globally in growth cones upon disinhibition of MS channels, but are most prominent in filopodia, as previous reported (Gomez et al., 2001). Both the incidence and frequency of $\mathrm{Ca}^{2+}$ transients increases upon inhibition relief of MS channels by AGA removal (Fig. $2 c, d$ ), and are reduced with GsMTx4 or Gd ${ }^{3+}$ (Fig. $2 a-d$ ). These results suggest that filopodial $\mathrm{Ca}^{2+}$ signals are likely generated by $\mathrm{Ca}^{2+}$ influx through a putative MS ion channel.

Since neurites extend faster on flexible FN-PDMS (Fig. 1), we predicted that the basal frequency of spontaneous $\mathrm{Ca}^{2+}$ transients may be less on flexible FN. Consistent with this notion, we find that both the frequency and incidence of spontaneous $\mathrm{Ca}^{2+}$ transients in filopodia are reduced in growth cones growing upon flexible FN (Fig. $2 c, d$ ). While the baseline $\left[\mathrm{Ca}^{2+}\right]_{\mathrm{i}}$ is not significantly different in growth cones on flexible versus rigid FN, neither the frequency of spontaneous filopodial $\mathrm{Ca}^{2+}$ transients nor the $\left[\mathrm{Ca}^{2+}\right]_{\mathrm{i}}$ increase upon removal of AGAs on flexible FN (Fig. $2 c-e)$. Together these results suggest that MS channels promote $\mathrm{Ca}^{2+}$ transients in growth cones through activation by mechanical forces generated through substratum attachment.

$\mathrm{Ca}^{2+}$ influx through MS channels increases calpain activity in growth cones

Local $\mathrm{Ca}^{2+}$ signals regulate axon outgrowth by activating effectors such as $\mathrm{Ca}^{2+}$-calmodulin-dependent protein kinase II 
a

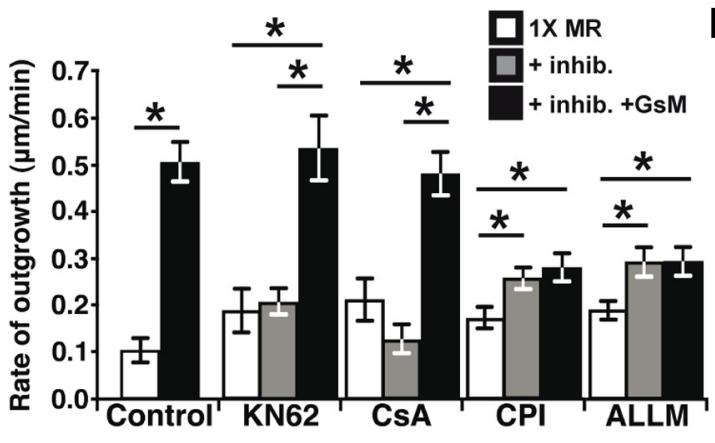

C

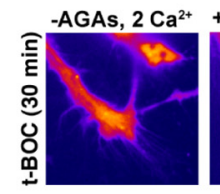

d

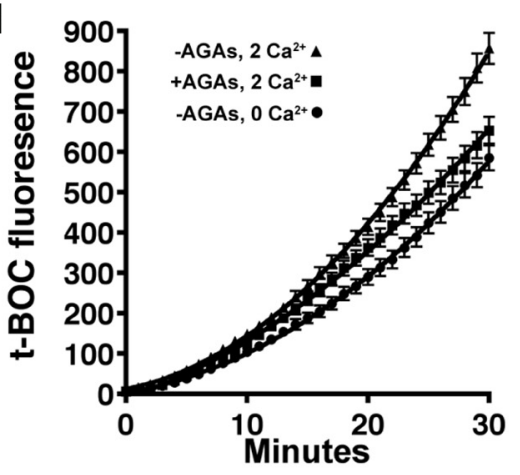

b

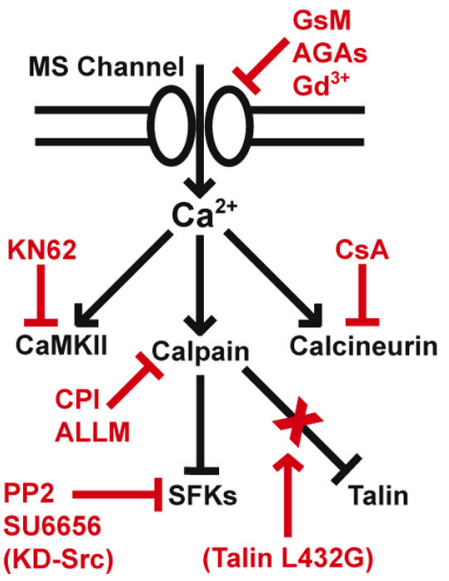

(Talin L432G)
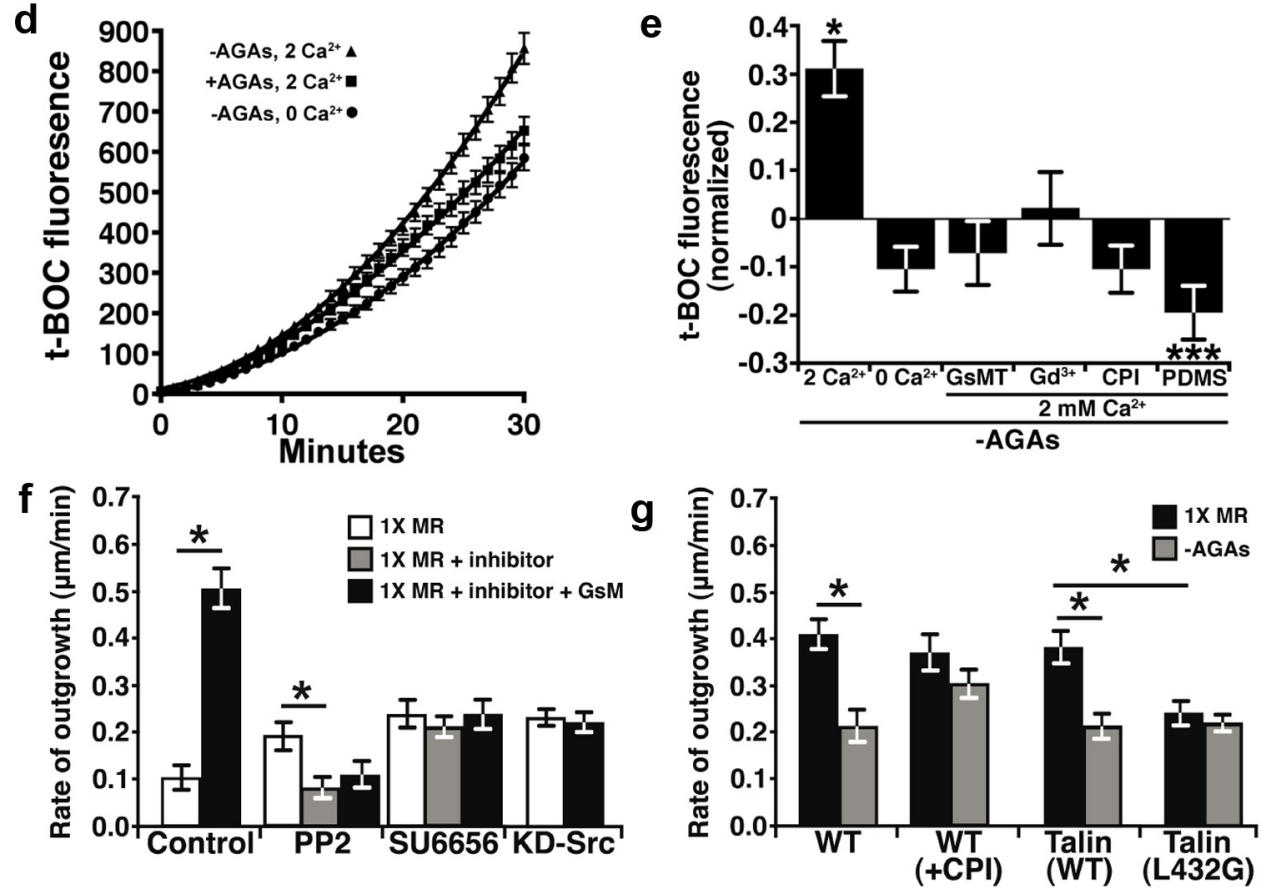

Figure 3. $\mathrm{Ca}^{2+}$ influx through MS channels activates calpain in growth cones. $\boldsymbol{a}$, The average rates of neurite outgrowth over 15 min periods before treatment (white bars), after the addition of inhibitors (gray bars), and after the subsequent addition of inhibitors with $10 \mu \mathrm{M}$ GSMTx4 (black bars). Inhibitors of $\mathrm{Ca}^{2+}$ effectors included the CaMKIl inhibitor KN62 (5 $\mu \mathrm{M}$ ), the calcineurin inhibitor (SA (10 nM), and the calpain protease inhibitors (1 $\mu \mathrm{M}$ (PI; $10 \mu \mathrm{M}$ ALLM). $\boldsymbol{b}$, A schematic diagram illustrates the $\mathrm{Ca}^{2+}$ signaling pathway (black) and inhibitors (red) used throughout this figure. Dominant-negative protein inhibitors are in parentheses. $c-e, A$ fluorogenic calpain substrate, $t-B O C$, was used to measure protease activity during activation and inhibition of $M S$ channels. c, Pseudocolored fluorescence images of growth cones loaded with t-BOC for 30 min under indicated conditions. Scale bar, $10 \mu \mathrm{m}$. $\boldsymbol{d}$, The intensities of t-BOC fluorescence (12-bit scale) plotted over 30 min with or without AGAs in 0 or $2 \mathrm{~mm} \mathrm{Ca}^{2+}$ ( $n \geq 83$ for each condition). $\boldsymbol{e}, \mathrm{t}-\mathrm{BOC}$ fluorescence intensity values measured at $30 \mathrm{~min}$ after $\mathrm{t}-\mathrm{BOC}$ addition and the baseline is normalized to control conditions in the presence of AGAs. Removing AGAs increases t-BOC fluorogenesis in the presence of $2 \mathrm{~mm} \mathrm{Ca}^{2+}$, but this is prevented in $0 \mathrm{~mm} \mathrm{Ca}{ }^{2+}$ and with MS channel blockers, with inhibition of calpain and in by growing neurons on flexible FN (PDMS).f, The rate of outgrowth was measured in the presence of inhibitors of Src family kinases included PP2 (1 $\mu \mathrm{m})$ and SU6656 (1 $\mu \mathrm{m})$, and in neurons expressing KD-Src. Control data are transferred from $\boldsymbol{a}$ for comparison. $\boldsymbol{g}$, The rate of outgrowth was quantified for 30 min before (black) and after (gray) the removal of AGAs in each condition. The removal of AGAs reduces the rate of outgrowth in wild-type and eGFP-Talin overexpressing neurons, but is blocked by the addition of $1 \mu \mathrm{m}$ CPI or expression of the calpain-resistant talin mutant, eGFP-Talin-L432G. ${ }^{*} p<0.05$ and ${ }^{* *} p<0.001$ using a Kruskal-Wallis test with a Dunn's post test.

(CaMKII), calcineurin phosphatase 1 (CaN-PP1), and the protease calpain (Robles et al., 2003; Wen et al., 2004). We identified calpain as a primary effector downstream of $\mathrm{Ca}^{2+}$ influx through MS channels, since pharmacological inhibition of calpain with the calpain protease inhibitors ( $1 \mu \mathrm{M}$ CPI or $10 \mu \mathrm{M}$ ALLM) not only stimulated axon outgrowth (Fig. $3 a$ ), but prevented the inhibitory effects of removing AGAs (Fig. 3g). This is consistent with our previous report that filopodial $\mathrm{Ca}^{2+}$ transients reduce axon outgrowth and repel axons through activation of calpain (Robles et al., 2003). Interestingly, axon outgrowth does not ac- celerate in response to GsMTx4 in the presence of the calpain inhibitors, suggesting that some calpain activity may be required for maximum outgrowth (Fig. 3a).

We further investigated the activation of calpain in growth cones by $\mathrm{Ca}^{2+}$ influx through MS channels by testing the effects of AGA removal while imaging calpain activity using the fluorogenic calpain substrate CMAC, $t$-BOC-Leu-Met ( $t-B O C)$. Here we find that the rate of calpain-dependent proteolysis is increased in growth cones on rigid FN upon disinhibition of MS channels by acute removal of AGAs (Fig. 3c-e). Activation of calpain is 
$\mathrm{Ca}^{2+}$ influx dependent, which is through MS channels, since the rate of t-BOC fluorogenesis is reduced in $0 \mathrm{mM} \mathrm{Ca}^{2+}$ (Fig. 3d,e) and with MS channel blockers in $2 \mathrm{mM} \mathrm{Ca}^{2+} \mathrm{MR}$ (Fig. 3e). Note that the level of calpain fluorogenesis when $\mathrm{Ca}^{2+}$ influx is blocked with MS channel inhibitors is similar to direct inhibition of calpain with CPI, suggesting that calpain is nearly completely inhibited when MS channel-dependent $\mathrm{Ca}^{2+}$ influx is blocked. Interestingly, growth cones on flexible $\mathrm{FN}$ had lower basal calpain activity (Fig. 3e), consistent with fewer $\mathrm{Ca}^{2+}$ transients in growth cones on flexible FN. Further, while inhibiting calpain stimulates axon extension on rigid FN (Fig. 3a), it has no effect on flexible FN, consistent with low basal levels of calpain activity (data not shown). We confirmed that changes in calpain activity can be detected on flexible FN by stimulating $\mathrm{Ca}^{2+}$ influx by depolarizing neurons with $40 \mathrm{mM} \mathrm{KCl}$ (data not shown). These results demonstrate that calpain is activated downstream of $\mathrm{Ca}^{2+}$ influx through MS channels, which are gated by mechanical forces generated through substratum attachment.

\section{Calpain cleaves talin to inhibit Src-dependent axon outgrowth}

We previously showed that calpain activity reduces axon outgrowth, but the specific proteolytic target(s) of calpain remain unknown. While direct targets of calpain were not identified in growth cones, we found that $\mathrm{Ca}^{2+}$ transients reduce the levels of tyrosine phosphorylation by Src family kinases (SFKs) in filopodia (Robles et al., 2003), suggesting calpain may cleave SFKs. Consistent with inhibition of SFK function by $\mathrm{Ca}^{2+} /$ calpain, we find that the growth-promoting effects of GsMTx4 are blocked by pharmacological inhibition of SFK and by overexpression of kinase dead Src (KD-Src; Fig. 3f). While Src may be directly cleaved by calpain (Oda et al., 1993), calpain-mediated cleavage of the integrin-binding protein talin is an important target that controls migration of non-neuronal cells (Franco et al., 2004). To test whether talin may regulate $\mathrm{Ca}^{2+}$ /calpain-dependent axon outgrowth, we expressed a talin point mutant (talin L432G), which is resistant to cleavage by calpain (Franco et al., 2004). Interestingly, we find that neurons expressing talin L432G, but not wild-type talin, are insensitive to the inhibitory effects of $\mathrm{Ca}^{2+}$ influx through MS channels (Fig. $3 g$ ), suggesting that talin is cleaved by calpain in growth cones. While neurons expressing talin L432G do have a reduced basal rate of axon outgrowth, this does not preclude these mutant neurons from responding to inhibitory effects of lysophosphatidic acid, which directly activates RhoA to inhibit outgrowth (data not shown) (Moon and Gomez, 2010).

Talin has previously been shown to localize within filopodia and to concentrate at filopodial tips (Letourneau and Shattuck, 1989; Renaudin et al., 1999), where it may activate $\beta 1$ integrin receptors (Calderwood et al., 1999). As we observe highfrequency $\mathrm{Ca}^{2+}$ transients at filopodial tips (Fig. 2), we predicted that $\mathrm{Ca}^{2+} /$ calpain activity may target talin at tips. To first determine the distribution of endogenous talin in Xenopus spinal neuron growth cones relative to adhesion sites, we immunolabeled talin together with the adhesion marker phosphotyrosine (pY)118-paxillin. Interestingly, we find that talin often concentrates at the tips of filopodia and in some cases it colocalizes with the point contact marker, pY118-paxillin (Fig. $4 a-c$ ). Moreover, we find that removing AGAs reduces pY118-paxillin and talin, but not F-actin, at the tips of filopodia (Fig. $4 d$ ). To examine the dynamic distribution of talin in neurons, we expressed eGFPtalin and imaged growth cones by time-lapse TIRF microscopy. Similar to endogenous talin, we find that eGFP-talin clusters at tips of extending filopodia (Fig. $4 e, f$ ) independent of volume differences (Fig. 4e,f). Next we tested whether the dynamic distribution of wild-type and the calpain-resistant talin (L432G) differed at baseline and after activation of $\mathrm{Ca}^{2+}$ influx through MS channels. Interestingly, we find that the frequency of talin assembly at filopodial tips was greater for wild-type talin compared with calpain-resistant talin (Fig. $4 k$ ). However, once assembled, calpain-resistant talin appears to remain at filopodial tips longer then wild-type talin, which may partially account for lower assembly frequency (Fig. $4 g-j, l)$. To examine the effects of $\mathrm{Ca}^{2+}$ influx through MS channels and the role of calpain on talin dynamics, we acutely removed AGAs in wild-type and mutant talin-expressing neurons. Consistent with calpain-dependent cleavage of talin, we find that disinhibition of MS channels reduced the frequency of assembly of wild-type talin, but not calpain-resistant talin at filopodial tips (Fig. $4 g-k$ ). Surprisingly, the duration talin spent at tips of filopodia was unaffected by MS channel activity (Fig. $4 g-i, l)$. However, consistent with previous results (Gomez et al., 2001; Robles et al., 2003) MS channel activity stabilizes filopodial tip motility in growth cones expressing wild-type talin, but not talin-L432G (Fig. $4 \mathrm{~m}$ ). Together, these data suggest that $\mathrm{Ca}^{2+}$ influx through MS channels activates calpain at filopodial tips, which cleaves talin to inhibit filopodial and growth cone motility.

\section{TRPC1 knockdown reduces the effects of acute changes in MS channel activity on axon outgrowth}

While identifying channels that are directly gated by mechanical forces has been elusive in many cell types, several members of the TRP family of channels are linked to MS currents in neurons. To determine whether $\mathrm{Ca}^{2+}$ influx through an MS TRP channel suppresses neurite outgrowth of Xenopus spinal neurons, we used antisense morpholino oligonucleotides (MO) to knock down the expression of two known MS TRP channels, TRPV4 and TRPC1. Both TRPC1 and TRPV4 are expressed in Xenopus spinal neurons (Shim et al., 2005; Wang and Poo, 2005) (Fig. 5a) and can assemble into $\mathrm{Ca}^{2+}$-permeable channels activated by various forms of mechanical stimuli (Strotmann et al., 2000; Maroto et al., 2005). The morpholinos we use in this study effectively knock down expression of TRPC1 and TRPV4 in Xenopus spinal neurons (Shim et al., 2005; Wang and Poo, 2005) (Fig. 5a). The effects of TRP channel knockdown were examined after 16-24 h in vitro by time-lapse video microscopy. Morpholino-positive neurons were identified by fluorescence (see Materials and Methods). The basal rates of neurite outgrowth for TRPV4 and TRPC1 morphant neurons were not significantly different compared with control morphant neurons (data not shown), suggesting some compensation occurred after chronic channel knockdown. However, the growth-promoting effects of GsMTx4 and inhibiting effects of AGA removal were prevented with TRPC1 knockdown (Fig. 5a,b). This is in contrast to TRPV4 morphant neurons, which accelerated similar to control morphant neurons in response to GsMTx4, and were only slightly inhibited by MS channel activation by removing AGAs (Fig. $5 b, c)$. Further support for TRPC1 function as an MS channel on growth cone filopodia comes from immunolocalization of TRPC1 along the length and at the tips of filopodia (Fig. $5 e-g$ ). For this we developed a TRPC1 antibody against a Xenopus-specific TRPC1 sequence (see Materials and Methods) and confirmed its specificity for TRPC1 by ICC in TRPC1 knockdown neurons (Fig. $5 d$ ). These results suggest that AGAs and GsMTx4, known MS channel antagonists, promote neurite outgrowth by blocking $\mathrm{Ca}^{2+}$ influx through TRPC1-containing channels. 

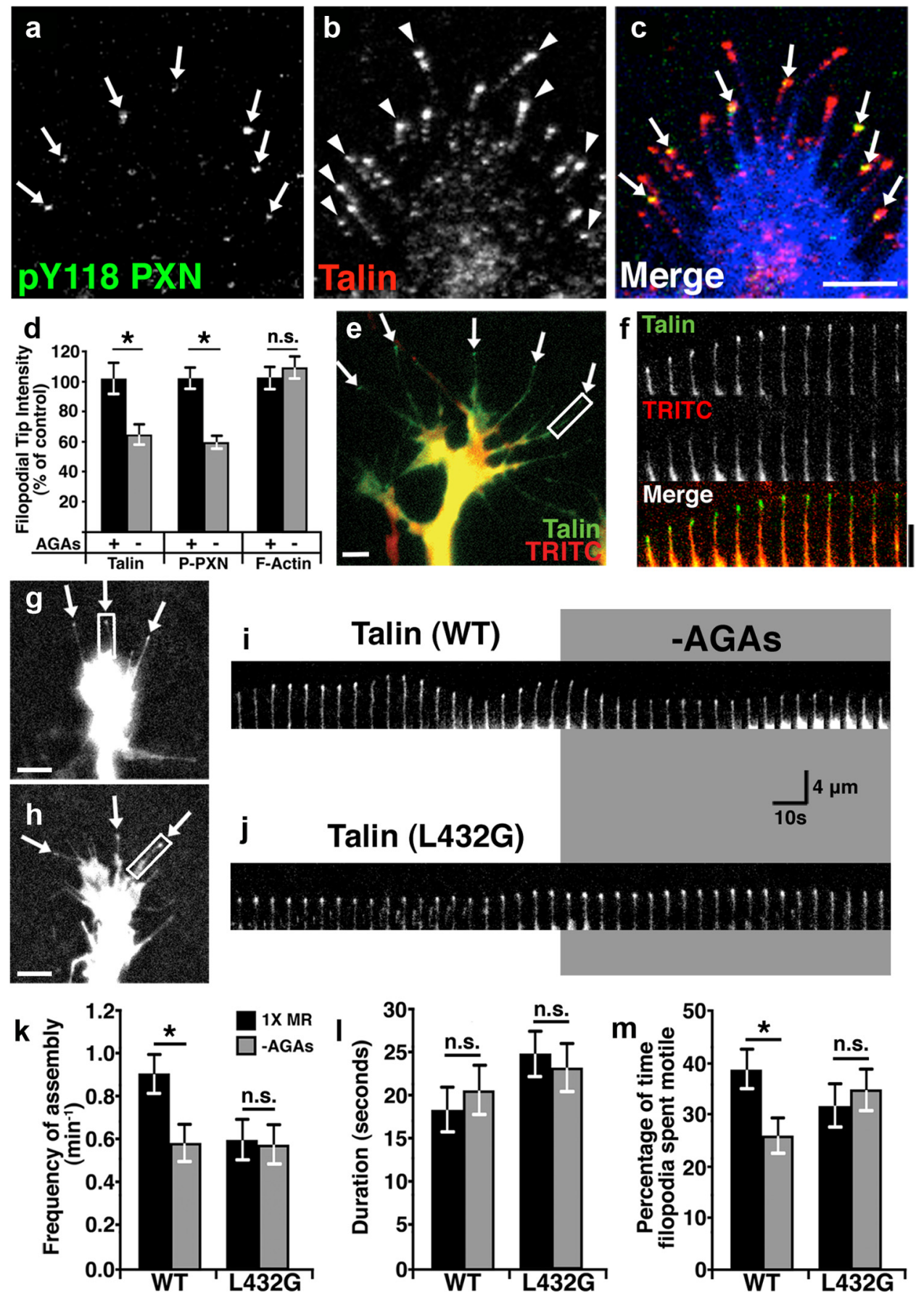

Figure 4. Proteolytic cleavage of talin by calpain reduces the dynamic assembly of talin at filopodial tips and filopodial motility. $\boldsymbol{a}-\boldsymbol{c}$, Representative images of a growth cone on $\mathrm{FN}$ immunostained for pY118-paxillin (a) and talin (b). Note thatpY118-paxillin (green) colocalizes with talin (red) at a subset of filopodial tips (arrows) in merged image (c), with phalloidin labeling of F-actin (blue). Arrowheads mark filopodial tips with only talin labeling.d, Quantification of the immunolabeling intensity at filopodial tips fortalin, pY118-paxillin, and F-actin exposed to 30 min with or without AGAs.e, Two-color image of a live neuron expressing eGFP-Talin (green) together with TRITC-dextran (red) as a volume marker. Note that eGFP-talin is enriched at the tips of filopodial (arrows). $\boldsymbol{f}$, A 1 min montage of a single filopodium denoted by the white box in e presented at 5 s intervals. EGFP-Talin fluorescence increases relative to TRITC at the tip of this extending filopodium. $\boldsymbol{g}, \boldsymbol{h}$, Wild-type (WT) eGFP-talin (g) and calpain-resistant eGFP-L432Gtalin (h) both localize to the tips of filopodia (arrows).i, A 200 s montage of a single filopodium expressing WT eGFP-talin denoted by the white boxin $\boldsymbol{g}$ presented at 5 s intervals. Note that this filopodium is motile with variable talin localization at the tip before AGA removal and that both the frequency of assembly and motility is reduced when AGAs are removed. $j$, A 200 s montage of a single filopodium expressing eGFP-L432G-talin denoted by the white box in $\boldsymbol{h}$ presented at 5 s intervals. Note that this filopodium is less motile and exhibits less dynamic talin at the tip and is unaffected by the removal of AGAs. $\boldsymbol{k}$, The mean frequency of assembly of both WT and calpain-resistant talin (L432G) before (black bars) and after (gray bars) the removal AGAs. $I$, The mean duration of both WT and calpain-resistant (L432G) talin was concentrated at filopodial tips before and after the removal of AGAs. $m$, The percentage of time filopodia extend or retract from growth cones expressing WT or $L 432 G$ mutant talin before and after removal of AGAs. ${ }^{*} p<0.05$ using a Kruskal-Wallis test with a Dunn's post test. Scale bars: $4 \mu \mathrm{m}$.

TRPC1 subunits form MS ion channels on growth cones Activation of TRPC1 channels by soluble axon guidance cues elevates cytosolic $\mathrm{Ca}^{2+}$ in Xenopus spinal neuron growth cones (Shim et al., 2005; Wang and Poo, 2005; Wen et al., 2007), but the channel responsible for mechanical force induced $\mathrm{Ca}^{2+}$ influx is unknown. Consistent with the normal basal rates of outgrowth we observed by TRPC1 morphant neurons, we find that the incidence and frequency of filopodial $\mathrm{Ca}^{2+}$ transients in TRPC1 
a

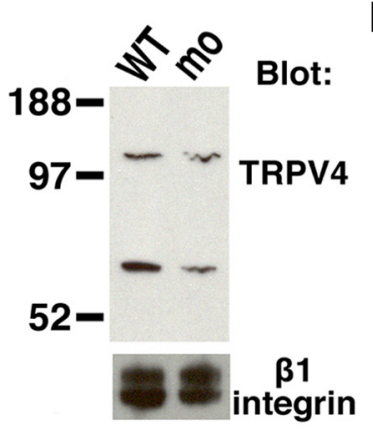

b

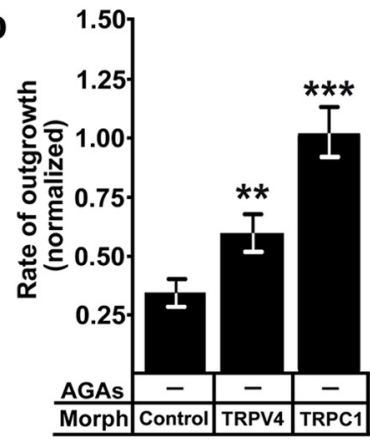

C

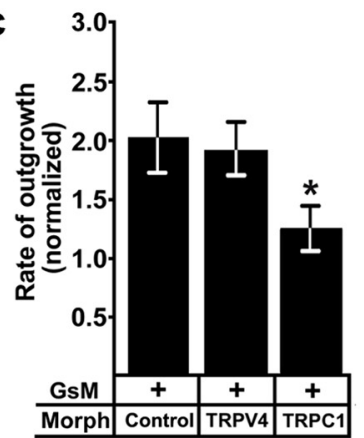

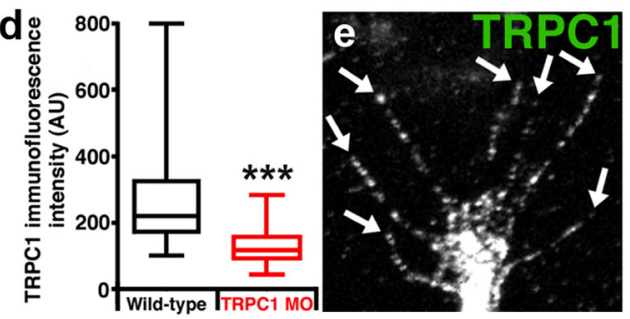
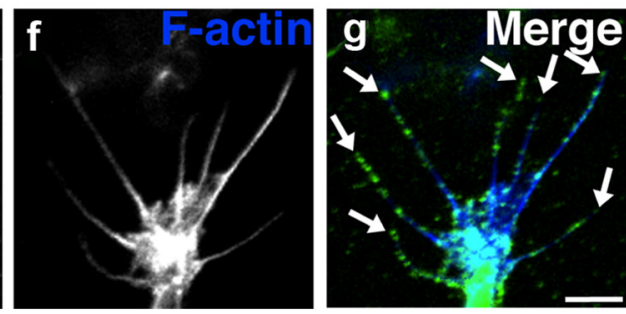

Figure 5. Morpholino-mediated knockdown of xTRPC1 reduces the effects of MS channel blockers on neurite outgrowth. $\boldsymbol{a}$, Western blot for TRPV4 from dorsal section lysates (see Materials and Methods) of control embryos and embryos injected with a TRPV4 morpholino (injected into 2 cells at the 4-cell stage). TRPV4 protein levels are reduced by $49.1 \pm 16.1 \%(n=4)$. As described previously in mouse, the TRPV4 protein appears as two bands of $\sim 107$ and $75 \mathrm{kDa}$, representing full-length TRPV4 and possibly a splice variant (Liedtke and Friedman, 2003). $\boldsymbol{b}$, The rate of neurite outgrowth on FN-coated glass in response to subtracting AGAs from neurons injected with control, TRPV4, or TRPC1 morpholinos normalized to the precondition rate of outgrowth ( $n \geq 42$ for each condition). $c$, The rate of neurite outgrowth on FN-coated glass in response to the addition of $10 \mu \mathrm{M}$ GsMTx4 from neurons injected with control, TRPV4, or TRPC1 morpholinos ( $n \geq 29$ for each condition). Statistical comparisons were made between control morphant neurons and TRP channel morphant neurons. $\boldsymbol{d}, \mathrm{A}$ box-and-whisker plot shows reduced TRPC1 immunofluorescence labeling in TRPC1 morphant growth cones. $\boldsymbol{e}-\boldsymbol{g}$, A representative growth cone immunolabeled for TRPC1 (e) and phalloidin to label F-actin $(\boldsymbol{f})$. $\boldsymbol{g}$, The merged image shows that TRPC1 (green) localizes with F-actin (blue) at the tips and along the shaft of filopodia (arrows). Scale bar, $4 \mu \mathrm{m} .{ }^{*} p<0.05$, ${ }^{* *} p<0.01$, and ${ }^{* * *} p<0.001$ using either a one-way ANOVA with a Tukey's post test (b) or a Kruskal-Wallis test with a Dunn's post test (c).

morphant neurons on rigid $\mathrm{FN}$ is not significantly different from control neurons (Fig. 6a,b). However, further activation of MS channels by removing AGAs does not significantly increase filopodial $\mathrm{Ca}^{2+}$ transients in TRPC1-deficient neurons (Fig. $6 a, b)$. In addition, baseline $\left[\mathrm{Ca}^{2+}\right]_{\mathrm{i}}$ changes, which occur upon removing AGAs, does not occur in TRPC1 knockdown neurons (Fig. $6 c, d$ ). As a more direct measure of MS channel activity, we used hypotonic solution to induce cell swelling and mechanical stimulation in neurons loaded with fura-2. Fura-2-loaded neurons treated with a hypotonic solution $(119 \mathrm{mOsm})$ typically exhibit a fast increase in $\left[\mathrm{Ca}^{2+}\right]_{i}$, followed by a prolonged elevation as described previously (Jacques-Fricke et al., 2006) (Fig. 6e). However, TRPC1 morphant neurons exhibit a significantly lower $\left[\mathrm{Ca}^{2+}\right]_{\mathrm{i}}$ after stimulation with hypotonic solution, suggesting loss of an MS channel (Fig. 6e). Addition of GsMTx4 in hypotonic solution led to a significant block of influx in control, but not TRPC1, morpholino-injected growth cones (Fig. 6e). Furthermore, we also found that knockdown TRPC1 expression reduced calpain proteolysis activity when MS channels were disinhibited by the removal of AGAs (Fig. $6 f$ ). Together these results suggest that TRPC1 forms an MS channel on filopodia that activates calpain to reduce neurite outgrowth.

\section{Local modulation of MS channels induces growth cone turning}

We previously reported that filopodial $\mathrm{Ca}^{2+}$ transients generated on one side of growth cones promotes repulsive turning (Gomez et al., 2001), which requires the activation of calpain (Robles et al., 2003). While stimulated local $\mathrm{Ca}^{2+}$ transients are sufficient to promote turning, it is unclear whether local modulation of MS channel activity specifically affects axon guidance. To test the effects of local MS channel activity, we examined growth cone turning in a gradient of GsMTx4 to locally suppress MS channel activity. As predicted, the majority of axons robustly orient toward the source of GsMTx4, turning at an average angle of $23.9 \pm$ 3.5 degrees, while no change in direction was observed with vehicle in the pipette (Fig. $7 a, b, g, h$ ). Growth cone turning to GsMTx4 was blocked without extracellular $\mathrm{Ca}^{2+}$, suggesting lo$\mathrm{cal} \mathrm{Ca}^{2+}$ influx was responsible (Fig. $7 c, g, h$ ). To test whether the guidance of axons by asymmetric inhibition of MS channels depends on substratum rigidity, we performed identical turning assays on neurons growing upon flexible FN. Interestingly, unlike on rigid FN, growth cones on flexible FN-PDMS exhibited no directional bias in a gradient of GsMTx4 (Fig. $7 d, g, h)$. Furthermore, we show that attraction to GsMTx4 requires TRPC1 subunits and calpain function, since knockdown of TRPC1 expression or pharmacological inhibition of calpain ablated growth cone attraction to GsMTx4 (Fig. 7e-h). These results are consistent with the notion that MS channels are more active on rigid FN and asymmetric inactivation of MS TRPC1 and calpain can induce attractive turning.

Since bath application of GsMTx4 accelerates neurite outgrowth by globally blocking filopodial $\mathrm{Ca}^{2+}$ transients (Figs. 1, 2), we predicted that graded GsMTx4 would promote attractive turning by locally suppressing $\mathrm{Ca}^{2+}$ transients in growth cones. To test this we imaged Fluo-4-loaded growth cones during initial exposure to gradients of GsMTx4 (see Materials and Methods). Quantifying the frequency of filopodial $\mathrm{Ca}^{2+}$ transients on distal versus proximal filopodia, we found that $\mathrm{Ca}^{2+}$ dynamics were more strongly reduced within proximal filopodia (Fig. $8 a-c$ ). Importantly, immediate differences in $\mathrm{Ca}^{2+}$ transient frequency across growth cones initially exposed to gradients of GsMTx4 coincides spatially and temporally with the direction rapid polarized membrane protrusion during turning (data not shown). 
a

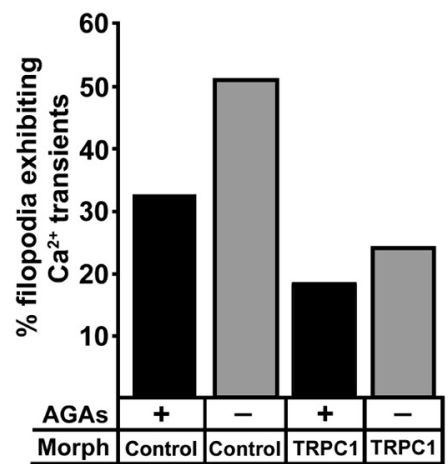

b

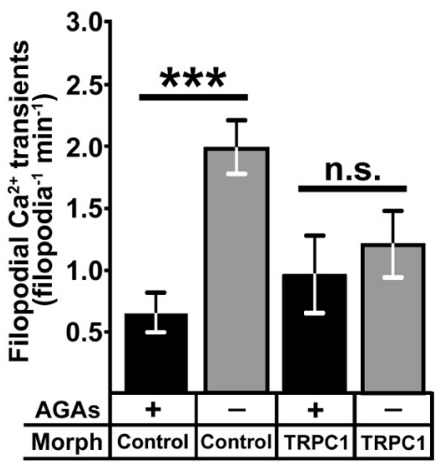

C

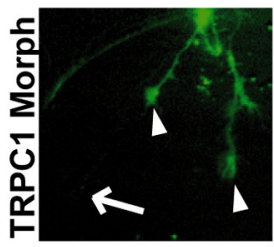

d
-AGAs

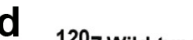

\section{ב}

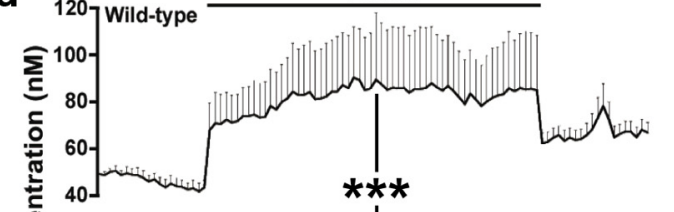

$* * *$
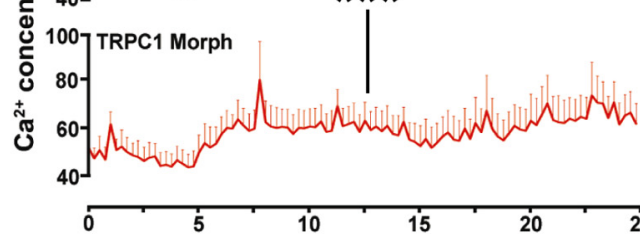

$\begin{array}{cccc}10 & 15 & 20 & 25 \\ \text { Time (minutes) } & & \end{array}$

f

e
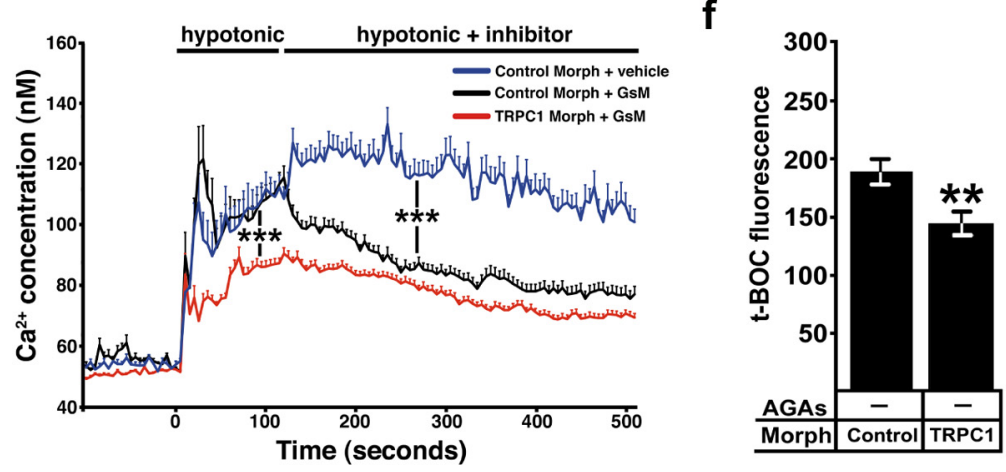

Figure 6. TRPC1 is required for mechanically induced $\mathrm{Ca}^{2+}$ influx and calpain protease activity in growth cones. $\boldsymbol{a}, \boldsymbol{b}$, Removing AGAs increases the incidence $(\boldsymbol{a})$ and frequency $(\boldsymbol{b})$ of filopodial $\mathrm{Ca}^{2+}$ transients in control morphant, but not TRPC1 morphant growth cones ( $n \geq 188$ filopodia for each condition, ${ }^{* * *} p<0.001$, Mann-Whitney test). $\boldsymbol{c}, \boldsymbol{d}$, Fura-2 ratiometric $\mathrm{Ca}^{2+}$ imaging shows that baseline $\left[\mathrm{Ca}^{2+}\right]_{\mathrm{i}}$ increases in wild-type, but not TRPC1 morphant growth cones during removal of AGAs. c, eGFP (top) was coinjected with the TRPC1 morpholino to identify TRPC1 knockdown (arrowheads) and wild-type (arrows) growth cones. Note that wild-type growth cones exhibit a higher fura- 2 ratio (bottom) compared with TRPC 1 knockdown growth cones. Scale bar, 10 $\mu \mathrm{m} . \boldsymbol{d}$, Quantification of $\left[\mathrm{Ca}^{2+}\right]_{\mathrm{i}}$ from wild-type and TRPC 1 knockdown growth cones over 25 min during removal of AGAs ( $n \geq$ 21 growth cones for each condition, ${ }^{* * *} p<0.001$, two-way ANOVA). $\boldsymbol{e}$, Fura-2 ratiometric measurement of growth cone $\left[\mathrm{Ca}^{2+}\right]_{\mathrm{i}}$ during mechanical stimulation with a hypotonic solution. In control morpholino growth cones, hypotonic solution induces a rapid increase in $\left[\mathrm{Ca}^{2+}\right]_{i}$, which is partially blocked with GsMTx4. In TRPC1 knockdown growth cones, elevation $\left[\mathrm{Ca}^{2+}\right]_{\mathrm{i}}$ in response to hypotonic solution is reduced and GsMTx4 causes no additional change ( $n \geq 26$ growth cone for each condition, ${ }^{* * *} p<0.001$, two-way ANOVA). Note that there is a significant residual $\mathrm{Ca}^{2+}$ elevation in response to hypotonic solution in TRPC1-morphant neurons, suggesting additional MS channels are expressed on growth cones. $f, t-B O C$ fluorescence intensity values measured at 30 min after t-BOC addition and AGA removal in TRPC 1 knockdown and control morpholino-injected neurons ( $n \geq 40$ growth cone for each condition, ${ }^{* *} p<0.01$, Mann-Whitney test).

However, in TRPC1 knockdown neurons, we observe no significant difference between proximal and distal filopodial $\mathrm{Ca}^{2+}$ transients in a gradient of GsMTx4 (Fig. 8d). Together these results suggest that asymmetric inhibition of MS-TRPC1 channels leads to an imbalance of filopodial $\mathrm{Ca}^{2+}$ transients sufficient to induce growth cone turning, consistent with our previous results on filopodial $\mathrm{Ca}^{2+}$ transients (Gomez et al., 2001; Robles et al., 2003).

\section{Discussion}

Previously we showed that pharmacological inhibition of MS channels on neuronal growth cones accelerates axon outgrowth (Jacques-Fricke et al., 2006; Gottlieb et al., 2010). Here we demonstrate that modulation of mechanical force-dependent $\mathrm{Ca}^{2+}$ signals through TRPC1 channels can regulate the rate and direction of axon extension. Mechanical forces within growth cones were modulated by adjusting the rigidity of the underlying cell substratum. Interestingly, we find that growth cones on compliant substrata exhibit fewer filopodial $\mathrm{Ca}^{2+}$ transients, lower calpain activity, and a faster rate of outgrowth. Consistent with dampened MS channel activity on compliant substrata, we find that adding or subtracting MS channel blockers has little effect on axon outgrowth of neurons on flexible FN. Specific knockdown of TRPC1 with antisense morpholinos identifies this subunit as an essential component of the MS channel found on growth cones. In addition, we provide new evidence that $\mathrm{Ca}^{2+}$ influx through MS-TRPC1 activates calpain, which cleaves talin that concentrates at the tips of filopodia. Finally, asymmetric inhibition of MS-TRPC1 channel activity with a gradient of GsMTx4 was sufficient to induce robust growth cone turning only on rigid FN. Together our results show that mechanical signals can directly regulate the speed and guidance of axons and suggest that mechanical cues may cooperate with classical chemical axon guidance cues in the assembly of the nervous system, as was recently suggested for axon guidance in the mammalian spinal cord (Moore et al., 2009, 2012).

$\mathrm{Ca}^{2+}$ signaling is necessary downstream of multiple axon guidance cues encountered by growth cones in the developing nervous system. The molecular basis for the differential effects of $\mathrm{Ca}^{2+}$ influx is likely through the activation of distinct $\mathrm{Ca}^{2+}$ effectors. For example, CaMKII and CaN-PP1 mediate attractive and repulsive turning to guidance cues, respectively (Wen et al., 2004). In addition, activation of the protease calpain by $\mathrm{Ca}^{2+}$ influx also promotes repulsive turning (Robles et al., 2003) and inhibits axon outgrowth on rigid substrata (Fig. 3). Calpain cleaves numerous target proteins, including a number of proteins that regulate cell adhesion and motility. We previously showed that calpain activity reduces the level of pY418-Src, which is involved in adhesion turnover (Robles et al., 2003; Robles and Gomez, 2006; Woo et al., 2009). However, the effect of calpain on pY418-Src could be indirect, as calpain cleaves adaptor proteins that indirectly complex with Src (Glading et al., 2002). For exam- 
a

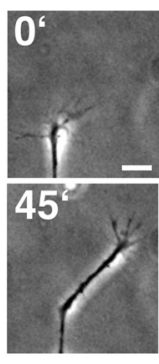

FN-Glass $2 \mathrm{Ca}^{2+}$

C

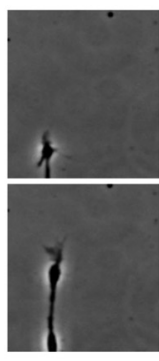

e

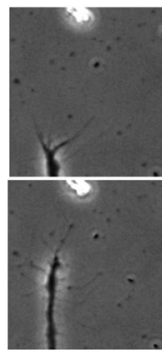

$20 \mu \mathrm{m}$ $2 \mathrm{Ca}^{2+}$ CPI

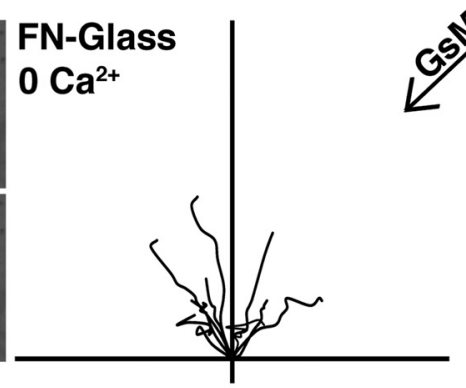

FN-Glass

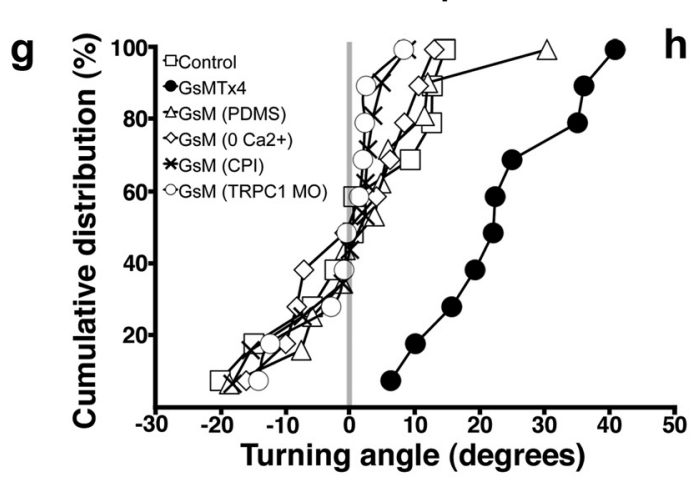

b

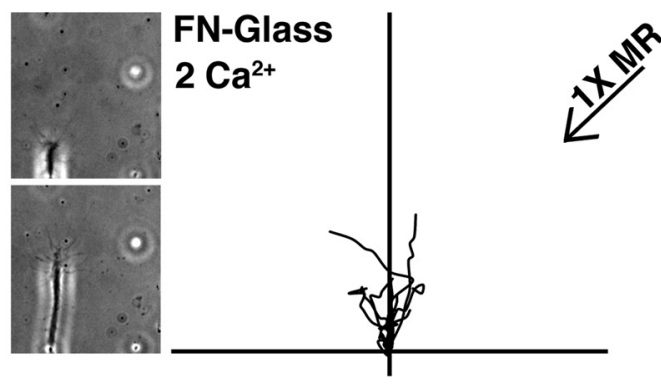

d

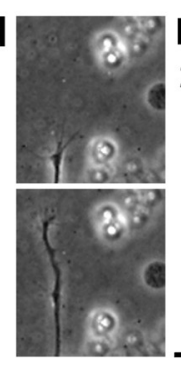

FN-PDMS $2 \mathrm{Ca}^{2+}$

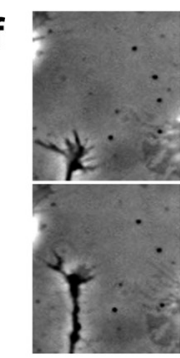

FN-Glass $2 \mathrm{Ca}^{2+}$ TRPC1 MO
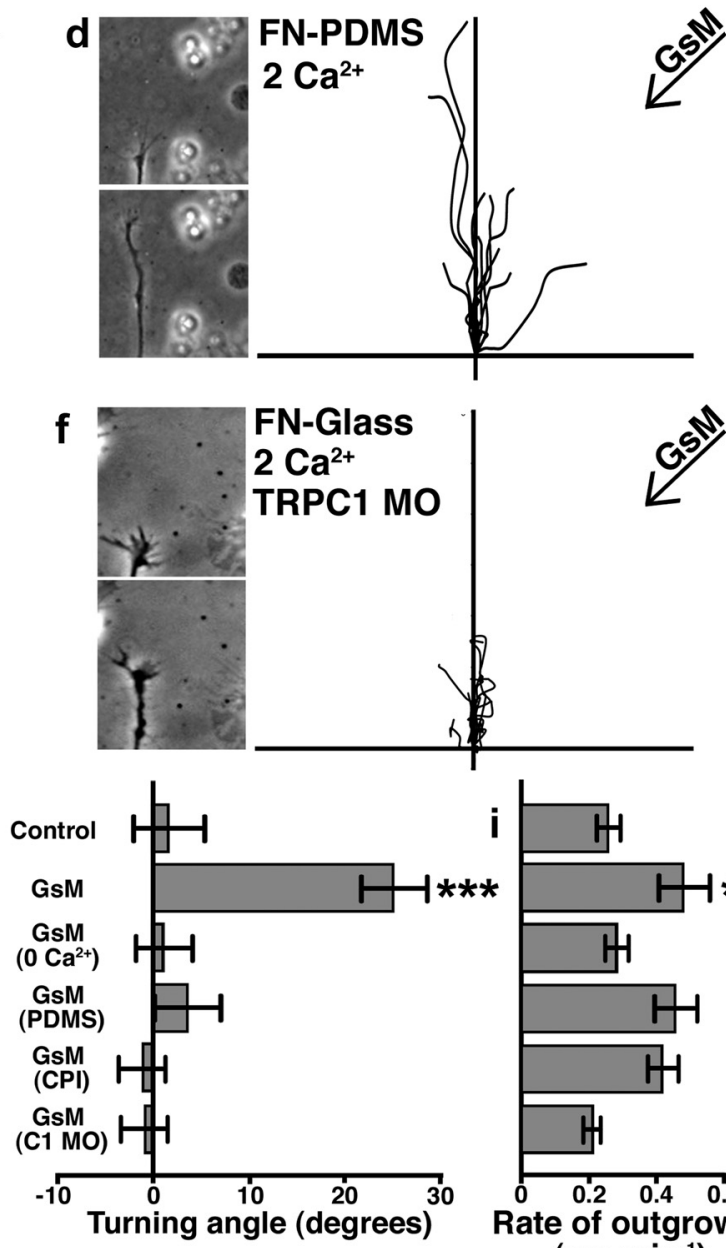

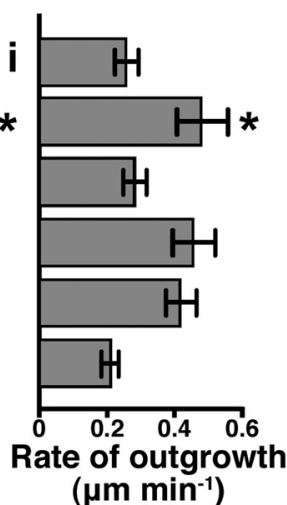

Figure 7. Asymmetric MS channel activity induces growth cone turning on rigid substrata. $\boldsymbol{a}$, Phase contrast images of a representative growth cone at the beginning (above) and end of a 45 min

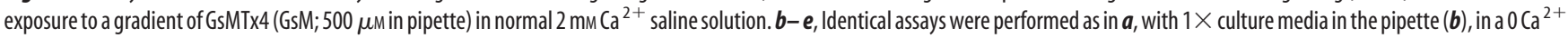
saline solution (c), with neurons plated onto a flexible FN-PDMS substratum ( $\boldsymbol{d}$ ), in the presence of $1 \mu \mathrm{M}$ CPI (e), and in TRPC1 M0 neurons (f). Axon trajectory traces of individual neurons shows the direction of outgrowth, with the leading edge of vertically oriented axons positioned at the plot origin at $t=0$ ( $n \geq 10$ for all conditions). Note that in a gradient of GsMTx4, neurons orient toward the pipette (indicated by arrow) and have longer trajectories, indicating an accelerated rate of outgrowth. $\boldsymbol{g}$, Cumulative distribution of growth cone turning angles for the conditions shown in $\boldsymbol{a}-\boldsymbol{f}$. $\boldsymbol{h}$, The mean turning angle ( \pm SEM) of each condition described in $\boldsymbol{a}-\boldsymbol{f}$. $\boldsymbol{i}$, Mean rate of axon outgrowth ( \pm SEM) for each condition described in $\boldsymbol{a}-\boldsymbol{f}$, ${ }^{*} p<0.05$ and ${ }^{* * *} p<0.001$ as compared with control assays with a $1 \times$ modified Ringer's gradient. All statistical analyses were completed with a Kruskal-Wallis test with a Dunn's post test.

ple, one principle target of calpain is talin, which both activates integrin receptors and links integrins to the actin cytoskeleton. In non-neuronal cells, talin plays key roles in the dynamics of adhesion turnover and cell motility (Franco et al., 2004). We find talin at the tips of filopodia (Fig. 4), which likely activates integrin receptors (Calderwood et al., 1999) and initiates point contact assembly to stabilize leading edge protrusions (Robles and Gomez, 2006). Colocalization of talin with pY118-paxillin in some filopodia (Fig. $4 a-c$ ) suggests these are nascent adhesions and are regulated by $\mathrm{Ca}^{2+}$ influx through MS channels (Fig. 4d). As rapid point contact turnover is associated with efficient neurite outgrowth (Myers and Gomez, 2011), $\mathrm{Ca}^{2+} /$ calpain activity may disrupt adhesion assembly or maturation through cleavage of talin.

$\mathrm{Ca}^{2+}$ signals through MS channels may be linked to specific $\mathrm{Ca}^{2+}$-mediated effectors within $\mathrm{Ca}^{2+}$ microdomains. A classic example of $\mathrm{Ca}^{2+}$ microdomains comes from presynaptic nerve terminals, as influx through specific voltage-gated ion channels are highly localized to synaptic vesicle fusion machinery (Wu et al., 1999). More recently, $\mathrm{Ca}^{2+}$ influx through TRPC5 and 
a

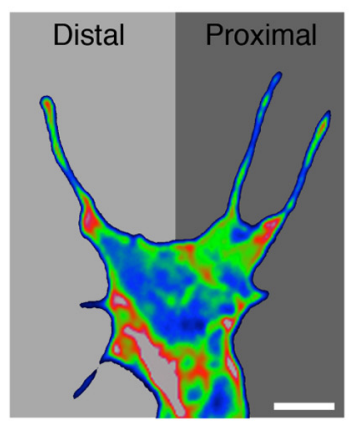

b

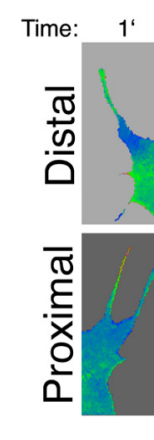

c

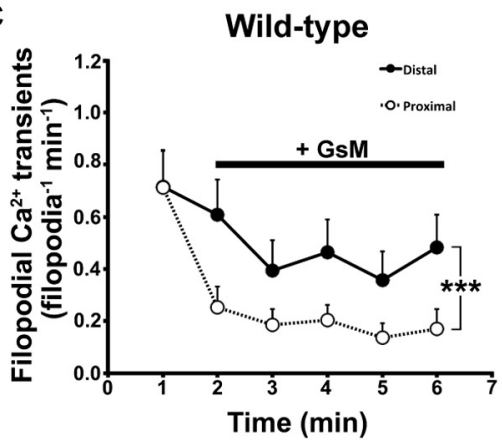

GsMTx-4 Gradient

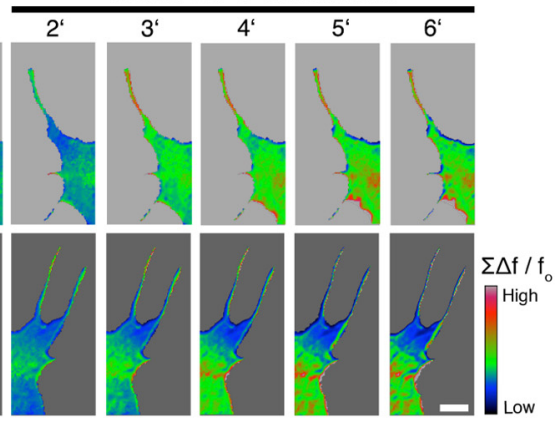

d

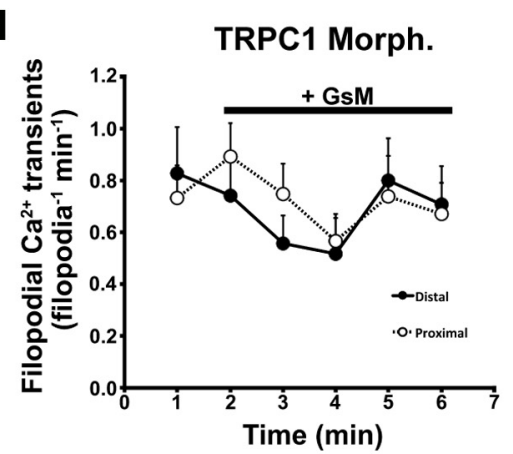

Figure 8. Local modulation of MS channels drives asymmetric filopodial $\mathrm{Ca}^{2+}$ transients. $\boldsymbol{a}$, A representative Fluo-4-loaded growth cone showing the division of proximal versus distal filopodial relative to a perpendicular gradient of GsMTx4 applied from the right. This image was generated by summing all frames of a 6 min time series captured at $1 \mathrm{~s}$ intervals. $\boldsymbol{b}$, Summed frames binned over 1 min time intervals show the changes in Fluo-4 intensity $\left(\sum \Delta f / f_{0}\right)$ during exposure to the GsMTx4 gradient (see Materials and Methods). Hot colors indicate that the frequency of filopodial $\mathrm{Ca}^{2+}$ transients was greater on the distal (upper) versus proximal (lower) side of this growth cone during the initial exposure to graded GsMTx4. c, The average ( \pm SEM) frequency of $\mathrm{Ca}^{2+}$ transients in proximal versus distal filopodia of growth cones in gradients of GsMTx4 in wild-type (c) or TRPC1 knockdown neurons (d). In wild-type, but not in TRPC1 knockdown neurons, distal filopodia exhibit a significantly higher frequency of $\mathrm{Ca}^{2+}$ transients compared with proximal within 1 min of gradient production ( ${ }^{* * *} p<0.001$, two-way ANOVA). Scale bars: $4 \mu \mathrm{m}$.

TRPC6 were linked to different Rho GTPases having opposite effects on cell motility (Tian et al., 2010). Similar processes also likely occur in growth cones, as our previous findings suggest (Jacques-Fricke et al., 2006). A number of different $\mathrm{Ca}^{2+}$ channels and receptors on intracellular stores may be associated with specific $\mathrm{Ca}^{2+}$ microdomains within growth cones. Both voltageoperated $\mathrm{Ca}^{2+}$ channels and a number of TRP channels on the plasma membrane function downstream axon guidance cues (Nishiyama et al., 2003; Li et al., 2005; Shim et al., 2005; Wang and Poo, 2005). Moreover, $\mathrm{Ca}^{2+}$ release from $\mathrm{IP}_{3}$ and ryanodine receptor stores is necessary for the chemoattractive effects of several guidance cues (Takei et al., 1998; Hong et al., 2000; Li et al., 2005). Interestingly, both attractive and repulsive guidance cues require $\mathrm{Ca}^{2+}$ influx through TRPC1 subunit-containing channels (Shim et al., 2005; Wang and Poo, 2005; Wen et al., 2007). In addition to chemical guidance cues, we show here that mechanical cues also stimulate $\mathrm{Ca}^{2+}$ influx through TRPC1-containing channels (Figs. 4, 5), consistent with previous studies in Xenopus oocytes (Maroto et al., 2005). How can TRPC1 subunits mediate the effects of such diverse stimuli? Subunit mixing occurs to form multiple unique channel tetramers, each with individual biophysical properties. For example, TRPC1 forms distinct channels by directly multimerizing TRPC4 and TRPC 5 subunits and may multimerize with TRPC3 and TRPC6 when in a complex with TRPC4 or TRPC5 (Strübing et al., 2003). Moreover, several novel TRPC subunit combinations were only found in the embryonic brain, suggesting important functions for unique TRPC channels in the developing nervous system (Strübing et al., 2003). Impor- tantly, these results suggest that antisense mediated knockdown of TRPC1 subunits could reduce the expression of multiple channel types and may explain how knocking down one TRPC subunit can prevent the effects of diverse chemical and mechanical cues.

How cells generate mechanical forces that activate MS TRP channels is poorly understood. Cells can generate internal forces by a number of means, including through polymerization/depolymerization of cytoskeletal components, by the movement of numerous molecular motors, and through osmotic cell swelling. Further, the actin cytoskeleton is often physically linked to surrounding cells and the extracellular matrix through molecular adhesion complexes bound to surface receptors (Myers et al., 2011). These linkages with an elastic extracellular microenvironment could regulate MS channel activation (Matthews et al., 2010). Mechanical stimulation through osmotic changes may directly or indirectly lead to TRP channel opening (Vriens et al., 2004; Loukin et al., 2010). Channel activation from lipid bilayer tension is supported by the strong effects we observe with GsMTx4 (Figs. 1, 2), which functions as an amphipathic channel blocker by lowering the lipid strain on MS channels (Suchyna et al., 2004). Furthermore, we find that direct manipulation of osmotic pressure activates $\mathrm{Ca}^{2+}$ influx that is partially through TRPC1-containing channels and blocked by GsMTx4 (Fig. 6e). It is noteworthy that recent evidence suggests that changes in osmolarity do not increase membrane tension, rather they increase the tension of the actin cytoskeleton (Spagnoli et al., 2008). While our results indicate that TRPC1 channels on growth cones may be gated by lipid forces, further evidence will be required to rule out gating of TRPC1 by the cytoskeleton.

The differentiation and behavior of cells is influenced by the elastic properties of their microenvironment (Wozniak and Chen, 2009). During development, tissue rigidity is believed to direct stem cell differentiation and tissue morphogenesis (Engler et al., 2006; Zhang et al., 2011). In particular, cell motility is strongly dependent on the compliance of the cell substratum (Moore et al., 2010). For example, fibroblasts migrate faster on flexible substrata, possibly due to increased focal adhesion turnover (Pelham and Wang, 1997). Similarly, extending neuronal processes exhibit enhanced axon outgrowth on compliant substrata (Willits and Skornia, 2004; Kostic et al., 2007). Regulation of $\mathrm{Ca}^{2+}$ influx may allow cells to sense substratum rigidity (Lee et al., 1999; Munevar et al., 2004). In this study we found that Xenopus spinal neuron growth cones grow faster on flexible FN due to reduced $\mathrm{Ca}^{2+}$ influx through TRPC1 channels. Moreover, we found that locally inhibiting MS TRPC1 with GsMTx4 on rigid FN produced robust attractive turning of neurons (Figs. 7, 8). These results suggest that disproportionate MS channel activity across growth cones is sufficient to orient axon outgrowth. However, turning toward GsMTx4 was prevented on flexible FN, suggesting that this condition globally silences MS channels on 
growth cones (Fig. $7 d-f$ ), which is consistent with a more rapid basal rate of outgrowth (Fig. 1c).

Neuronal processes in vivo innervate many tissues with widely varying elastic moduli. While the environments supporting axon outgrowth in vivo are often more flexible than the substrata tested here, it is clear that axons do extend upon tissues of widely varying elasticity in vivo (Discher et al., 2005). For example, tissue elasticities range from highly compliant brain tissue (1-10 kPa) to more rigid tissues such as muscle $(12-100 \mathrm{kPa})$ or highly rigid bone (30 GPa) (Moore et al., 2010). Therefore, the differences ourselves and others observe with cell motility on varying substratum elasticities likely parallel neuronal behaviors within varying elastic environments in vivo (Pelham and Wang, 1997; Lo et al. 2000; Munevar et al. 2004, Willits and Skornia, 2004). However, few studies have addressed the roles of mechanical signals in neural development. Future studies should attempt to specifically target MS TRPC channels, but since individual subunits contribute to distinct multimers, removing a single subunit may disrupt numerous channel types. A more specific manipulation of MS channels may come through blocking the upstream signal transduction cascades that activate MS channels (Vriens et al., 2004; Matthews et al., 2010) or by mutating key residues of MS channels.

\section{References}

Alderton JM, Steinhardt RA (2000) Calcium influx through calcium leak channels is responsible for the elevated levels of calcium-dependent proteolysis in dystrophic myotubes. J Biol Chem 275:9452-9460. CrossRef Medline

Calderwood DA, Zent R, Grant R, Rees DJ, Hynes RO, Ginsberg MH (1999) The Talin head domain binds to integrin beta subunit cytoplasmic tails and regulates integrin activation. J Biol Chem 274:28071-28074. CrossRef Medline

Dent EW, Meiri KF (1992) GAP-43 phosphorylation is dynamically regulated in individual growth cones. J Neurobiol 23:1037-1053. CrossRef Medline

Discher DE, Janmey P, Wang YL (2005) Tissue cells feel and respond to the stiffness of their substrate. Science 310:1139-1143. CrossRef Medline

Doyle A, Marganski W, Lee J (2004) Calcium transients induce spatially coordinated increases in traction force during the movement of fish keratocytes. J Cell Sci 117:2203-2214. CrossRef Medline

Engler AJ, Sen S, Sweeney HL, Discher DE (2006) Matrix elasticity directs stem cell lineage specification. Cell 126:677-689. CrossRef Medline

Franco SJ, Rodgers MA, Perrin BJ, Han J, Bennin DA, Critchley DR, Huttenlocher A (2004) Calpain-mediated proteolysis of talin regulates adhesion dynamics. Nat Cell Biol 6:977-983. CrossRef Medline

Frey MT, Tsai IY, Russell TP, Hanks SK, Wang YL (2006) Cellular responses to substrate topography: role of myosin II and focal adhesion kinase. Biophys J 90:3774-3782. CrossRef Medline

Glading A, Lauffenburger DA, Wells A (2002) Cutting to the chase: calpain proteases in cell motility. Trends Cell Biol 12:46-54. CrossRef Medline

Gomez TM, Zheng JQ (2006) The molecular basis for calcium-dependent axon pathfinding. Nat Rev Neurosci 7:115-125. CrossRef Medline

Gomez TM, Robles E, Poo M, Spitzer NC (2001) Filopodial calcium transients promote substrate-dependent growth cone turning. Science 291: 1983-1987. CrossRef Medline

Gómez TM, Harrigan D, Henley J, Robles E (2003) Working with Xenopus spinal neurons in live cell culture. Methods Cell Biol 71:129-156. CrossRef Medline

Gottlieb PA, Barone T, Sachs F, Plunkett R (2010) Neurite outgrowth from PC12 cells is enhanced by an inhibitor of mechanical channels. Neurosci Lett 481:115-119. CrossRef Medline

Grynkiewicz G, Poenie M, Tsien RY (1985) A new generation of Ca2+ indicators with greatly improved fluorescence properties. J Biol Chem 260: 3440-3450. Medline

Henley J, Poo MM (2004) Guiding neuronal growth cones using Ca2 + signals. Trends Cell Biol 14:320-330. CrossRef Medline

Hong K, Nishiyama M, Henley J, Tessier-Lavigne M, Poo M (2000) Calcium signalling in the guidance of nerve growth by netrin-1. Nature 403:93-98. CrossRef Medline

Jacques-Fricke BT, Seow Y, Gottlieb PA, Sachs F, Gomez TM (2006) Ca2+ influx through mechanosensitive channels inhibits neurite outgrowth in opposition to other influx pathways and release from intracellular stores. J Neurosci 26:5656-5664. CrossRef Medline

Kostic A, Sap J, Sheetz MP (2007) RPTPalpha is required for rigiditydependent inhibition of extension and differentiation of hippocampal neurons. J Cell Sci 120:3895-3904. CrossRef Medline

Kroese AB, Das A, Hudspeth AJ (1989) Blockage of the transduction channels of hair cells in the bullfrog's sacculus by aminoglycoside antibiotics. Hear Res 37:203-217. CrossRef Medline

Lee J, Ishihara A, Oxford G, Johnson B, Jacobson K (1999) Regulation of cell movement is mediated by stretch-activated calcium channels. Nature 400:382-386. CrossRef Medline

Liedtke W, Friedman JM (2003) Abnormal osmotic regulation in trpv4-/mice. Proc Natl Acad Sci U S A 100:13698-13703. CrossRef Medline

Letourneau PC, Shattuck TA (1989) Distribution and possible interactions of actin-associated proteins and cell adhesion molecules of nerve growth cones. Development 105:505-519. Medline

Li Y, Jia YC, Cui K, Li N, Zheng ZY, Wang YZ, Yuan XB (2005) Essential role of TRPC channels in the guidance of nerve growth cones by brain-derived neurotrophic factor. Nature 434:894-898. CrossRef Medline

Liu M, Sun J, Sun Y, Bock C, Chen Q (2009) Thickness-dependent mechanical properties of polydimethylsiloxane membranes. J Micromech Microeng 19:3.

Lo CM, Wang HB, Dembo M, Wang YL (2000) Cell movement is guided by the rigidity of the substrate. Biophys J 79:144-152. CrossRef Medline

Loukin S, Zhou X, Su Z, Saimi Y, Kung C (2010) Wild-type and brachyolmia-causing mutant TRPV4 channels respond directly to stretch force. J Biol Chem 285:27176-27181. CrossRef Medline

Maroto R, Raso A, Wood TG, Kurosky A, Martinac B, Hamill OP (2005) TRPC1 forms the stretch-activated cation channel in vertebrate cells. Nat Cell Biol 7:179-185. CrossRef Medline

Matthews BD, Thodeti CK, Tytell JD, Mammoto A, Overby DR, Ingber DE (2010) Ultra-rapid activation of TRPV4 ion channels by mechanical forces applied to cell surface betal integrins. Integr Biol 2:435-442. CrossRef

Moon MS, Gomez TM (2010) Balanced Vav2 GEF activity regulates neurite outgrowth and branching in vitro and in vivo. Mol Cell Neurosci 44:118 128. CrossRef Medline

Moore SW, Biais N, Sheetz MP (2009) Traction on immobilized netrin-1 is sufficient to reorient axons. Science 325:166. CrossRef Medline

Moore SW, Roca-Cusachs P, Sheetz MP (2010) Stretchy proteins on stretchy substrates: the important elements of integrin-mediated rigidity sensing. Dev Cell 19:194-206. CrossRef Medline

Moore SW, Zhang X, Lynch CD, Sheetz MP (2012) Netrin-1 Attracts Axons through FAK-Dependent Mechanotransduction. J Neurosci 32:1157411585. CrossRef Medline

Munevar S, Wang YL, Dembo M (2004) Regulation of mechanical interactions between fibroblasts and the substratum by stretch-activated Ca2+ entry. J Cell Sci 117:85-92. CrossRef Medline

Myers JP, Gomez TM (2011) Focal adhesion kinase promotes integrin adhesion dynamics necessary for chemotropic turning of nerve growth cones. J Neurosci 31:13585-13595. CrossRef Medline

Myers JP, Santiago-Medina M, Gomez TM (2011) Regulation of axonal outgrowth and pathfinding by integrin-ECM interactions. Dev Neurobiol 71:901-923. CrossRef Medline

Nguyen QT, Sanes JR, Lichtman JW (2002) Pre-existing pathways promote precise projection patterns. Nat Neurosci 5:861-867. CrossRef Medline

Nishiyama M, Hoshino A, Tsai L, Henley JR, Goshima Y, Tessier-Lavigne M, Poo MM, Hong K (2003) Cyclic AMP/GMP-dependent modulation of $\mathrm{Ca} 2+$ channels sets the polarity of nerve growth-cone turning. Nature 423:990-995. CrossRef Medline

Oda A, Druker BJ, Ariyoshi H, Smith M, Salzman EW (1993) pp60src is an endogenous substrate for calpain in human blood platelets. J Biol Chem 268:12603-12608. Medline

Ostrow KL, Mammoser A, Suchyna T, Sachs F, Oswald R, Kubo S, Chino N, Gottlieb PA (2003) cDNA sequence and in vitro folding of GsMTx4, a specific peptide inhibitor of mechanosensitive channels. Toxicon 42:263274. CrossRef Medline

Pelham RJ Jr, Wang Y (1997) Cell locomotion and focal adhesions are reg- 
ulated by substrate flexibility. Proc Natl Acad Sci U S A 94:13661-13665. CrossRef Medline

Rajnicek A, McCaig C (1997) Guidance of CNS growth cones by substratum grooves and ridges: effects of inhibitors of the cytoskeleton, calcium channels and signal transduction pathways. J Cell Sci 110:2915-2924. Medline

Renaudin A, Lehmann M, Girault J, McKerracher L (1999) Organization of point contacts in neuronal growth cones. J Neurosci Res 55:458-471. CrossRef Medline

Robles E, Gomez TM (2006) Focal adhesion kinase signaling at sites of integrin-mediated adhesion controls axon pathfinding. Nat Neurosci 9:1274-1283. CrossRef Medline

Robles E, Huttenlocher A, Gomez TM (2003) Filopodial calcium transients regulate growth cone motility and guidance through local activation of calpain. Neuron 38:597-609. CrossRef Medline

Robles E, Woo S, Gomez TM (2005) Src-dependent tyrosine phosphorylation at the tips of growth cone filopodia promotes extension. J Neurosci 25:7669-7681. CrossRef Medline

Shackelford JF, Alexander W (2001) CRC materials science and engineering handbook, Ed 3. Boca Raton, FL: CRC.

Shim S, Goh EL, Ge S, Sailor K, Yuan JP, Roderick HL, Bootman MD, Worley PF, Song H, Ming GL (2005) XTRPC1-dependent chemotropic guidance of neuronal growth cones. Nat Neurosci 8:730-735. CrossRef Medline

Spagnoli C, Beyder A, Besch S, Sachs F (2008) Atomic force microscopy analysis of cell volume regulation. Phys Rev E Stat Nonlin Soft Matter Phys 78:031916. CrossRef Medline

Strotmann R, Harteneck C, Nunnenmacher K, Schultz G, Plant TD (2000) OTRPC4, a nonselective cation channel that confers sensitivity to extracellular osmolarity. Nat Cell Biol 2:695-702. CrossRef Medline

Strübing C, Krapivinsky G, Krapivinsky L, Clapham DE (2003) Formation of novel TRPC channels by complex subunit interactions in embryonic brain. J Biol Chem 278:39014-39019. CrossRef Medline

Suchyna TM, Tape SE, Koeppe RE 2nd, Andersen OS, Sachs F, Gottlieb PA (2004) Bilayer-dependent inhibition of mechanosensitive channels by neuroactive peptide enantiomers. Nature 430:235-240. CrossRef Medline

Takei K, Shin RM, Inoue T, Kato K, Mikoshiba K (1998) Regulation of nerve growth mediated by inositol 1,4,5-trisphosphate receptors in growth cones. Science 282:1705-1708. CrossRef Medline

Tian D, Jacobo SM, Billing D, Rozkalne A, Gage SD, Anagnostou T, Pavenstädt H, Hsu HH, Schlondorff J, Ramos A, Greka A (2010) Antagonistic regulation of actin dynamics and cell motility by TRPC5 and TRPC6 channels. Sci Signal 3:ra77. CrossRef Medline
Vriens J, Watanabe H, Janssens A, Droogmans G, Voets T, Nilius B (2004) Cell swelling, heat, and chemical agonists use distinct pathways for the activation of the cation channel TRPV4. Proc Natl Acad Sci U S A 101: 396-401. CrossRef Medline

Wang GX, Poo MM (2005) Requirement of TRPC channels in netrin-1induced chemotropic turning of nerve growth cones. Nature 434:898904. CrossRef Medline

Wei C, Wang X, Chen M, Ouyang K, Song LS, Cheng H (2009) Calcium flickers steer cell migration. Nature 457:901-905. CrossRef Medline

Wen Z, Guirland C, Ming GL, Zheng JQ (2004) A CaMKII/calcineurin switch controls the direction of $\mathrm{Ca}(2+)$-dependent growth cone guidance. [see comment]. Neuron 43:835-846. CrossRef Medline

Wen Z, Han L, Bamburg JR, Shim S, Ming GL, Zheng JQ (2007) BMP gradients steer nerve growth cones by a balancing act of LIM kinase and Slingshot phosphatase on ADF/cofilin. J Cell Biol 178:107-119. CrossRef Medline

Willits RK, Skornia SL (2004) Effect of collagen gel stiffness on neurite extension. J Biomater Sci Polym Ed 15:1521-1531. CrossRef Medline

Woo S, Rowan DJ, Gomez TM (2009) Retinotopic mapping requires focal adhesion kinase-mediated regulation of growth cone adhesion. J Neurosci 29:13981-13991. CrossRef Medline

Wozniak MA, Chen CS (2009) Mechanotransduction in development: a growing role for contractility. Nat Rev Mol Cell Biol 10:34-43. CrossRef Medline

Wu LG, Westenbroek RE, Borst JG, Catterall WA, Sakmann B (1999) Calcium channel types with distinct presynaptic localization couple differentially to transmitter release in single calyx-type synapses. J Neurosci 19: 726-736. Medline

Wu LJ, Sweet TB, Clapham DE (2010) International Union of Basic and Clinical Pharmacology. LXXVI. Current progress in the mammalian TRP ion channel family. Pharmacol Rev 62:381-404. CrossRef Medline

Xu SZ, Zeng F, Lei M, Li J, Gao B, Xiong C, Sivaprasadarao A, Beech DJ (2005) Generation of functional ion-channel tools by E3 targeting. Nat Biotechnol 23:1289-1293. CrossRef Medline

Yang XC, Sachs F (1989) Block of stretch-activated ion channels in Xenopus oocytes by gadolinium and calcium ions. Science 243:1068-1071. CrossRef Medline

Zhang H, Landmann F, Zahreddine H, Rodriguez D, Koch M, Labouesse M (2011) A tension-induced mechanotransduction pathway promotes epithelial morphogenesis. Nature 471:99-103. CrossRef Medline 